\title{
Friendship Quality of Early Adolescent Girls in relation to Maternal and Paternal Parenting, Social Anxiety, and Interpersonal Skill
}

Joanna T. Prout

West Virginia University

Follow this and additional works at: https://researchrepository.wvu.edu/etd

\section{Recommended Citation}

Prout, Joanna T., "Friendship Quality of Early Adolescent Girls in relation to Maternal and Paternal Parenting, Social Anxiety, and Interpersonal Skill" (2014). Graduate Theses, Dissertations, and Problem Reports. 523.

https://researchrepository.wvu.edu/etd/523

This Dissertation is protected by copyright and/or related rights. It has been brought to you by the The Research Repository @ WVU with permission from the rights-holder(s). You are free to use this Dissertation in any way that is permitted by the copyright and related rights legislation that applies to your use. For other uses you must obtain permission from the rights-holder(s) directly, unless additional rights are indicated by a Creative Commons license in the record and/ or on the work itself. This Dissertation has been accepted for inclusion in WVU Graduate Theses, Dissertations, and Problem Reports collection by an authorized administrator of The Research Repository @ WVU.

For more information, please contact researchrepository@mail.wvu.edu. 
Friendship Quality of Early Adolescent Girls in relation to Maternal and Paternal Parenting, Social Anxiety, and Interpersonal Skill

Joanna T. Prout, MS

Dissertation submitted to the Eberly College of Arts and Sciences at West Virginia University

in partial fulfillment of the requirements for the degree of

Doctor of Philosophy

in

Psychology

Tracy L. Morris, Ph.D., Chair

Elisa Krackow, Ph.D.

Michael Perone, Ph.D.

Carrie Rishel, Ph.D.

Natalie Shook, Ph.D.

Department of Psychology

Morgantown, West Virginia

2014

Keywords: Social Anxiety, Friendship Quality, Parenting, Adolescents Copyright 2014 Joanna Prout 


\begin{abstract}
Friendship Quality of Early Adolescent Girls in relation to Maternal and Paternal Parenting, Social
\end{abstract}

Anxiety, and Interpersonal Skill

Joanna T. Prout, MS

Social anxiety has been shown to negatively impact friendship quality across the lifespan, leading to relationships that are less intimate and emotionally supportive. In turn, lower friendship quality and lack of social support have been linked to increased risk for isolation and depression. Early adolescence is a period of transition when the basis of friendship shifts from the ability to be a good play partner to the ability to engage in more complex interpersonal skills such as self-disclosure, provision of emotional support, and assertiveness. The early adolescent period is also a time when levels of social anxiety increase as children become more aware of how they are perceived by peers. Therefore, socially anxious children, who often possess social skills deficits, may be at increased risk for problems with friendship during this time period. Limited research has looked at possible associations between social anxiety and the interpersonal skills used in friendships during the early adolescent period. In addition, parenting, both before and during early adolescence, has been linked to children's levels of anxiety and interpersonal skill. However, most research concerning parenting and child anxiety has focused on anxiety in general, rather than social anxiety specifically. Further, most work has focused solely on the influence of mothers. The purpose of the current study was to address gaps in the literature concerning the influence of both maternal and paternal parenting on social anxiety, interpersonal skill, and friendship quality in a sample of early adolescent girls. Family triads $(\mathrm{N}=67)$ including male and female caregivers and a daughter between the ages of 12 and 14 completed questionnaires regarding parental autonomy-granting and communication. Adolescents completed measures of parental psychological control, social anxiety, interpersonal skill, and friendship quality. Maternal psychological control was positively associated with adolescent social anxiety and negatively associated with adolescent interpersonal skill and friendship quality. Maternal communication was negatively associated with adolescent social anxiety and positively associated with adolescent interpersonal skill and friendship quality. No significant associations were found between paternal variables and adolescent outcomes. As expected, a strong negative association was found between adolescent social anxiety and adolescent interpersonal skill. Adolescent interpersonal skill also showed a positive association with adolescent friendship quality. Limitations of the current research as well as implications and future directions are discussed. 


\begin{abstract}
Acknowledgements
I would like to express my gratitude to all of my committee members for their helpful input during this process. I would like to thank Dr. Tracy Morris for sticking with me through a graduate career that included surprises both bad and good. I would also like to thank Dr. Michael Perone for introducing me to behaviorism and implanting the phrase "molecular, not molar" in my "mind" almost immediately after I arrived at WVU. I would also like to acknowledge Dr. Elisa Krackow for her constant support

throughout my time at WVU, including her guidance in clinical work and case conceptualization. I want to express my sincere gratitude to my officemate and friend, Vanessa Jacoby, for her boundless ability to listen and remain positive in the face of graduate school adversity. Finally, I would like to thank my parents and husband for their support throughout my life and graduate school career. Without them, none of this would have been possible.
\end{abstract}




\section{Table of Contents}

Title Page

i

Abstract

ii

Acknowledgements

iii

Table of Contents

iv

List of Figures

1

List of Tables

2

Introduction

3

Method

20

Participants

20

Measures

22

Procedure

26

Results

26

Discussion

32

$\begin{array}{ll}\text { References } & 40\end{array}$

$\begin{array}{lr}\text { Figures } & 54\end{array}$

$\begin{array}{lr}\text { Tables } & 58\end{array}$

$\begin{array}{ll}\text { Appendix A } & 62\end{array}$ 


\section{List of Figures}

1. Mediation of the Relation between Maternal Psychological Control and Adolescent Friendship Quality by Adolescent Social Anxiety

2. Mediation of the Relation between Paternal Psychological Control and Adolescent Friendship Quality by Adolescent Social Anxiety

3. Mediation of the Relation between Maternal Communication and Adolescent Friendship Quality by Adolescent Interpersonal Skill

4. Mediation of the Relation between Paternal Communication and Adolescent Friendship Quality by Adolescent Interpersonal Skill 
List of Tables

1. Demographic Characteristics of Participants

2. Descriptive Statistics for Variables

3. Differences in Variables by Race

4. Correlations between Variables 
Friendship Quality of Early Adolescent Girls in relation to Maternal and Paternal Parenting, Social Anxiety, and Interpersonal Skill

Normative social development requires that as children move into adolescence and adulthood, they must shift their primary source of social support from parents to peers and eventually to romantic partners (Bierman, 2004). For most individuals, this progression occurs with little difficulty; however, children with high levels of social anxiety often experience chronic peer relationship problems beginning as early as the pre-school years (Morris, 2001). Socially-anxious and shy children and adults have been found to exhibit social skills deficits during performance situations or interactions with unfamiliar people (Beidel, Turner, Young, Ammerman, Sallee, \& Crosby, 2007; Pilkonis, 1977; Spence, Donovan, \& Brechman-Toussaint, 1999). In addition, several studies have suggested that social anxiety is associated with poor interpersonal skills such as low levels of positive affect, assertion, and self-disclosure during interactions with familiar people, including friends and romantic partners (Rubin, Daniels-Beirness, \& Bream, 1984; Schneider, 1999; 2009; Wenzel, Graff-Dolezal, Macho, \& Brendle, 2005).

However, while research has found that heightened social anxiety is associated with problematic relationship skills for children under the age of 12 (e.g., Schneider, 1999; 2009) and adults (e.g., Arroyo \& Harwood, 2011; Sparrevohn \& Rapee, 2009); only limited work has examined the link between social anxiety and adolescents' behavior within the context of friendships (for exceptions see Vernberg, Abwender, Ewell, Beery, 1992; Biggs, Vernberg, \& Wu, 2012). This lack of research is surprising given that multiple theorists have emphasized that adolescence is a period when the skills needed for adult relationships are acquired through the formation of intense same-sex friendships (Adelson \& Douvan, 1975; Selman, 1981; Sullivan, 1953). Further, research has consistently shown that childhood peer problems predict adjustment problems that continue into adulthood (Bagwell, Newcomb, \& Bukowski, 1998; Parker \& Asher, 1987). 
While the development of peer relationships is an integral part of adolescence, parents also continue to play an important role in adolescents' social and emotional adjustment (Engels, Dekovic, \& Meeus, 2002; Engels, Finkenauer, Dekovic, \& Meeus, 2001). Research concerning children's social development has emphasized the interconnection between the interpersonal spheres of the family and the peer group (McDowell \& Parke, 2009; Parke \& Ladd, 1992). Parents have been shown to be influential in both children's development of social anxiety (de Vente, Majdandžić, Colonnesi, \& Bögels, 2011; Bögels, Stevens, \& Majdandžić, 2011) and their development of interpersonal skills (Cook \& Fletcher, 2012; McDowell \& Parke, 2009). However, research has largely been limited to the impact of parenting on outcomes in pre-adolescents and to the impact of mothers on children's behavior. The current study adds to the existing literature by examining associations among parenting, social anxiety, interpersonal skill, and friendship quality in a sample of early adolescents and their mothers and fathers.

\section{Social Anxiety and Friendship Quality}

Social anxiety has been defined as fear and avoidance of situations involving interaction with unfamiliar people or possible scrutiny and evaluation by others (American Psychiatric Association, 2000). Symptoms of social anxiety may involve heightened physiological arousal, thoughts reflecting fear of negative evaluation by others, and attempts to avoid or escape from feared social situations (Morris \& Ale, 2011). Social fears show a dramatic increase from childhood to adolescence, becoming the highestrated type of fear between the ages of 13 and 16 (Westenberg, Gullone, Bokhorst, Heyne, \& King, 2007). Assessments of the prevalence of social anxiety in adolescents have found that while many adolescents may not meet full criteria for social anxiety disorder, a significant number report experiencing social fears. In a study by Essau, Conradt, and Peterman (1999), approximately 47\% of adolescents reported having at least one social fear, with the most commonly cited being performing in front of others, public speaking, and informal social discussions. 
While social anxiety is often thought of as impacting the ability to form new relationships, research indicates that it also may be linked to poor-quality friendships (Biggs et al., 2012; Wenzel et al., 2005). The association between social anxiety and lower friendship quality has been apparent even in research using samples of young children (e.g., Rubin, Wojslawowicz, Rose-Krasnor, Booth-Laforce, \& Burgess, 2006). This effect is unfortunate as supportive friendships are thought to be essential for children's current adjustment and social development (Piaget, 1932; Sullivan, 1953). High-quality friendships have been associated with high self-esteem, positive school adjustment, and protection from peer victimization (Bagwell et al., 1998; Crawford \& Manassis, 2011; Hodges, Malone, \& Perry, 1997; Ladd, 1990). Additionally, children showing anxious solitary behavior have been found to be at increased risk for depression, especially if excluded by peers (Gazelle \& Rudolph, 2004).

The idea that socially anxious and shy children experience both reduced friendship quality and receive decreased benefits from their friendships has been supported by a number of questionnaire-based studies. Using a sample of 827 fifth-grade students, Rubin and colleagues (2006) compared friendship quality in a group of children identified as shy and a group of children identified as low in both shyness and aggressiveness. Shy children were found to be equally likely as control children to have a mutual stable best-friendship. However, when compared to control children, shy children rated their friendships as having lower levels of help and guidance, less intimate disclosure, and poorer conflict resolution. In a similar study using a sample of forty-eight 8-to10-year old children, both shy children and friends they had selected completed a questionnaire measure of friendship quality (Fordham \& Stevenson-Hinde, 1999). When compared to their friends' ratings, shy children were found to rate their friendship as being lower in quality. Greco and Morris (2005) found that in a sample of 333 children between the ages of 8 and 12 social anxiety was associated with negative friendship quality for both boys and girls. Further, for girls only, social anxiety was negatively related to positive friendship quality. 
The negative association between social anxiety and friendship quality appears to continue as children move into adolescence; although when gender effects are examined, the damaging impact of social anxiety on friendship quality may be more apparent for girls than boys (e.g., La Greca \& Lopez, 1998). La Greca and Lopez (1998) studied the relationships among social anxiety, peer group acceptance, and friendship quality in 250 tenth- through twelfth-graders. For girls only, a significant relationship was found between heightened social anxiety and fewer friendships. Further, socially-anxious girls reported lower levels of intimacy, companionship, and support in their friendships when compared to non-anxious girls. In a more recent study, La Greca and Harrison (2005) examined the relationship between social anxiety and friendship quality in a sample of 421 adolescents between the ages of 14 and 19 . As predicted, lower levels of social anxiety were associated with more positive interactions within a bestfriendship; whereas higher levels of social anxiety were associated with more negative interactions. Similarly, in a study of 83 seventh- and eighth-grade girls, Starr and Davila (2008) found that even after controlling for depressive symptoms, high social anxiety was related to lower levels of trust and communication within friendships.

Initial research has indicated that social withdrawal may mediate the relationship between social anxiety and poor friendship quality (Biggs et al., 2012; Vernberg et al., 1992). In a longitudinal study of 68 children between the ages of 12 and 14 who had relocated within the past three months, Vernberg and colleagues (1992) found that distress and avoidance of general social situations led to fewer interactions with friends, which in turn contributed to lower levels of intimacy within friendships. In an extension of this study, social withdrawal was found to mediate the relationship between social anxiety and friendship quality in a sample of 214 early adolescents (Biggs et al., 2012). However, both of these studies examined the mediating impact of avoidance of situations where interaction with friends was possible. There may be other mechanisms which contribute to the relationship between social anxiety and poor 
friendship quality, including use of maladaptive communication behaviors during interactions with friends (Rubin et al., 1984; Schneider, 1999; 2009).

\section{Social Anxiety and Interpersonal Behavior}

Theories describing the interpersonal context of social anxiety state that socially-anxious individuals' heightened distress during interactions with others leads to maladaptive thoughts and behaviors which increase the likelihood of social rejection (Alden \& Taylor, 2004). According to selfpresentation theories of social anxiety, while most individuals aim to gain positive evaluation from others during social interactions, socially-anxious individuals aim to avoid negative evaluation (Arkin, Lake, \& Baumgartner, 1986; Leary, Kowalski, \& Campbell, 1988; Weeks, Rodebaugh, Heimberg, Norton, \& Jakatdar, 2009). This fear of negative evaluation, along with heightened distress, is thought to lead socially-anxious individuals to use a communication style characterized by low rates of speech, limited self-disclosure, low positive and high negative affect, and avoidance of assertion (Arkin et al., 1986). These behaviors may inadvertently lead to interpersonal rejection, the very result feared by the sociallyanxious individual (Alden \& Taylor, 2004).

Several studies have tested the self-presentation theory of social anxiety by comparing the behaviors of socially-anxious and non-anxious adults during interactions with unfamiliar people (Alden \& Bieling, 1998; Heery \& Kring, 2007). In a study of 120 unfamiliar adults engaged in a "getting to know you" conversation, the behavior patterns of dyads containing either two non-anxious individuals or one socially-anxious and one non-anxious individual were compared (Heery \& Kring, 2007). When compared to non-anxious pairs, pairs containing a socially-anxious person showed more fidgeting and fewer reciprocal smiles. Further, when compared to non-anxious participants, socially-anxious participants asked fewer questions and engaged in more self-focused talk and reassurance-seeking. These behaviors were found to contribute to the relationship between social anxiety and lower partner ratings of interaction quality. In a similar study by Alden and Bieling (1998), 41 socially-anxious and 41 non- 
anxious adults engaged in a conversation with an unfamiliar person. Prior to the interaction, participants' expectations were manipulated through provision of information that they were likely to have a positive or negative experience during the conversation. In the negative-expectancy condition only, sociallyanxious participants showed lower rates of speech and chose less intimate conversation topics. In turn, these behaviors contributed to lower ratings of appropriateness and likeability.

Existing research suggests that socially-anxious children and adolescents also show social skills deficits during interactions with peers (Beidel et al., 2007; Gazelle, Putallaz, Li, Grimes, Kupersmidt, \& Coie, 2005; Spence et al., 1998). In a comparison of 27 children between the ages of 7 and 14 who had been diagnosed with social anxiety disorder (SAD) and a matched non-clinical group, socially-anxious children were found to make fewer social initiations, be less likely to receive positive peer responses, and to spend less overall time in social interaction when observed in a school setting (Spence et al., 1998). In a similar study employing a slightly older age group, Beidel and colleagues (2007) compared the social skills of 63 children aged 13 to 16 who had been diagnosed with SAD and 43 age-and-gender- matched control children. When the behavior of each group of children was compared during role plays with a similarly-aged peer, children with SAD were rated by independent evaluators as appearing significantly more anxious and less socially-skilled than control children. Gazelle and colleagues (2005) compared the social interactions of 209 fourth-grade girls identified as anxious solitary or behaviorally normative in two contexts, play groups with familiar and unfamiliar peers. When compared to girls identified as behaviorally normative, girls identified as anxious solitary showed poorer social skills, including more awkward transitions into interactions, less frequent communication, and lower levels of positive affect. While the between-group difference in social skill was apparent in both contexts, there was a trend for anxious-solitary girls to show improved social skills over time in the unfamiliar peer group only.

While these studies have provided support for a link between social anxiety and interpersonal skill deficits during interactions with unfamiliar individuals, research across both child and adult 
populations has indicated that social anxiety may also be related to use of a self-protective communication style when talking to friends and romantic partners (Rubin et al., 1984; Schneider, 1999, 2009; Sparrevohn \& Rapee, 2009; Wenzel et al., 2005). Research examining children's interpersonal behavior has shown an association between social anxiety and lower rates of speech and positive affect during interactions with friends and familiar peers (Rubin et al., 1984; Schneider, 1999; 2009). For example, in an observational study of 53 kindergarten students interacting with a known peer, Rubin and colleagues (1984) found that when compared to non-shy children, shy children had lower rates of speech and made fewer requests. Similarly, using a sample of 58 dyads of 8-and-9-year-old friends, Schneider (1999) found that socially-withdrawn children spoke significantly less and engaged in less friendly competition when compared to non-withdrawn children. In an extension of this research involving 76 dyads of 10-to-12-year old children, Schneider (2009) found that during an interaction with a best friend, socially-anxious children spoke less, were less assertive, and displayed less positive affect when compared to non-anxious children.

Research using adult samples has shown a similar association between social anxiety and problematic patterns of communication within romantic relationships (Sparrevohn \& Rapee, 2009; Wenzel et al., 2005). For example, using a sample of 38 adults diagnosed with SAD and 58 community controls, Sparrevohn and Rapee (2009) found that when compared to controls, socially-anxious participants reported less self-disclosure, emotional expression, and overall intimacy within their romantic relationships. Further, when compared to control participants, participants with SAD reported overall lower relationship quality.

Although few observational studies of the interactions of socially-anxious adults and their romantic partners have been conducted, existing research supports the idea that communication deficits associated with social anxiety may contribute to relationship problems. For example, Wenzel and colleagues (2005) observed 27 socially-anxious and non-anxious young adults and their romantic partners 
discussing neutral, negative, and positive topics. Across all three conversations, socially-anxious participants showed fewer positive behaviors such as accepting responsibility, requesting clarification, using empathy, complimenting their partner, and using humor. Additionally, during a discussion of a problem the couple was experiencing, socially-anxious individuals showed more negative behaviors such as lack of understanding of partner's viewpoint, using put-downs, bringing up other issues, pointing out partner's character flaws, and summarizing themselves only. Notably, partners' conversational behaviors did not differ by group.

While only a handful of studies on the topic have been conducted to date, existing research supports the idea that social anxiety impairs friendship quality in adults (Rodebaugh, 2009; Rodebaugh, Fernandez, \& Levinson, 2012). Further, initial studies have shown that the association between social anxiety and poor relationship quality may be at least in part accounted for by poor interpersonal skills. For example, Arroyo and Harwood (2011) compared the same-sex friendships of shy and non-shy undergraduate students by having students and friends complete questionnaire measures of communication competence and relationship quality. As predicted, a relationship between shyness and lower relationship quality was found. Further, this relationship was mediated by the shy person's lower ability to communicate effectively with the friend.

\section{Social Development during Adolescence}

As one of the primary tasks of adolescence is to build social support outside of the family, the presence of high-quality peer relationships may be particularly important for positive adjustment during this time (Adelson \& Douvon, 1975). According to Sullivan (1953), intense same-sex friendships or “chumships" emerge in pre- or early adolescence (children aged 9 to 12) to meet emerging needs for support and validation from peers. As the presence of intimate friendships becomes more important for positive adjustment during adolescence, the skills needed to be successful in friendships also become more complex during this time period (Berndt, 1982). While childhood friendships are based on 
enjoyment of shared activities and being a good play partner, adolescent friendships require interpersonal skills such as appropriate self-disclosure, providing emotional support, and managing conflict (Buhrmester, Furman, Wittenberg, \& Reis, 1988).

In an early study by Buhrmester and Furman (1987) the relative importance of family members and peers in the provision of companionship and intimacy was examined in a sample of 313 second-, fifth-, and eighth-grade students. As predicted, family members were identified as primary sources of companionship for second- and fifth-graders, whereas this relationship was weaker among eighth-graders. As the importance of family members for companionship decreased with age, the importance of same-sex peers increased. Similarly, parents were found to be more important sources for intimate disclosure for elementary-aged participants when compared to eighth-grade participants. Examination of gender differences revealed that girls expected intimate disclosure in friendships at an early age when compared to boys.

Buhrmester (1990) conducted an extension of this study using the Adolescent Interpersonal Competence Questionnaire (AICQ; Buhrmester, 1990), to examine friendship intimacy and interpersonal skills in 102 preadolescents between the ages of 10 and 13 and 70 adolescents between the ages of 13 and 16. The AICQ was designed to assess the skills needed for the more complex relationships of adolescence and adulthood, including self-disclosure, provision of emotional support, management of conflict, negative assertion, and initiation of contact with friends. Contrary to expectations, no significant difference in level of friendship intimacy was found between the preadolescent and adolescent groups. However, friendship intimacy was found to correlate with global measures of adjustment; with higher intimacy predicting greater sociability and self-esteem and lower levels of hostility, anxiety, and depression. Further, self-rated friendship intimacy showed a stronger association with social and emotional well-being among adolescents when compared to pre-adolescents. Also, scores on the AICQ were significantly correlated with measures of friendship intimacy, suggesting that youth with better 
interpersonal skills also had higher-quality friendships. Girls were found to rate friendships as significantly more intimate when compared to boys.

Research has consistently found differences in the friendships of boys and girls, many of which emerge during early adolescence (for a review see Rose \& Rudolph, 2006). More specifically, within the context of friendships, girls spend more time in social conversation and report higher levels of selfdisclosure when compared to boys (e.g., Buhrmester \& Furman, 1987; Rose, 2002). Further, when compared to boys, adolescent girls endorse a greater need for closeness within relationships and report more fear of abandonment and loneliness (Rose \& Rudolph, 2006). Multiple studies have found that girls report higher levels of self-disclosure within their friendships when compared to boys (e.g., Buhrmester, 1990; Buhrmester \& Furman, 1987) and initial work indicates that social anxiety may damage girls' friendships to a greater extent than boys' friendships (e.g., La Greca \& Lopez, 1998). As social anxiety has been linked to deficits in self-disclosure and assertion within friendships (e.g., Cuming \& Rapee, 2010; Arroyo \& Harwood, 2011) and these behaviors may be more essential to high-quality friendships for females than males, it follows that social anxiety may have a greater negative impact on female versus male friendships.

\section{Parenting and Social Anxiety}

Parental control and rejection have been consistently linked with negative child outcomes, including heightened social anxiety (e.g., van der Bruggen, Stams, \& Bogels, 2008). Parental control may take various forms including what has been termed psychological control, or intrusive involvement in children's experiences and attempts to manipulate children's thoughts, emotions, and behaviors (Barber, 1996). Parental control may also be manifested through a lack of autonomy granting, or tendency to promote the child's dependence on the parent rather than encourage the child's independent functioning (Silk, Morris, Kanaya, \& Steinberg, 2003). Both high levels of psychological control and low levels of autonomy granting have been related to the development of anxiety and depressive symptoms in 
youth (Barber, Xia, Olsen, McNeely, \& Bose, 2012; Silk et al., 2003). Parental rejection, or low level of care, has been defined as a lack of warmth and responsiveness or tendency towards overt criticism during interactions with children (Clark \& Ladd, 2000). Research has accumulated to support the idea that while both parental control and rejection may contribute to childhood psychopathology; control may be more strongly associated with childhood anxiety (e.g., McLeod, Wood, \& Weisz, 2007; Rapee, 1997; van der Brugge et al., 2008).

Initial studies examining the relationship between parental rejection and control and offspring anxiety involved adults' retrospective reports of their parents' behavior towards them during childhood. Work by Arrindell and colleagues found that when compared to control participants, outpatients with social anxiety disorder rated their parents as being lower in care and higher in overprotection (Arrindell, Kwee, Methorst, Van der Ende, Pols, \& Moritz, 1989; Arrindell, Emmelkamp, Monsma, \& Brilman, 1983). In related research, Parker found that in a community sample of adults, low maternal care was associated with elevated anxiety and depression; whereas high maternal overprotection showed a unique association with elevated anxiety (Parker, 1979). An extension of this study comparing adults diagnosed with anxiety disorders to adults with no diagnoses showed that anxious adults were more likely than controls to rate both their fathers and their mothers as being low in care and high in overprotection (Parker, 1981).

The limitations of linking retrospectively-reported parenting behavior with adult anxiety led to research examining concurrent parenting and child anxiety. Studies using samples of pre-school and school-age children provided evidence that mothers of anxious children were more likely to show overcontrol and rejection during interactions with their children when compared to mothers of non-anxious children. In a study of 120 mothers and their preschool-aged children, Dumas and LaFreniere (1993) found that mothers of anxious children showed higher levels of negativity than mothers of control children during a puzzle task. In a similar study of mothers and children between the ages of 2 and 6 , 
mothers and socially-competent children were found to engage in positive exchanges with low levels of coercion when the child was asked to complete a cognitive task (Dumas, LaFreniere, \& Serketich, 1995). In contrast, mothers and anxious children had highly aversive interactions, with both members of the dyad using coercive attempts at control.

Research involving samples of pre-adolescents and adolescents has shown a similar relationship between maternal over-control and child anxiety. Krohne and Hock (1991) observed the interactions of mothers of anxious and non-anxious children between the ages of 10 and 13 as they worked on a problem-solving task. For female children only, mothers with anxious children were more likely than mothers of non-anxious children to act in an over-controlling manner during the task. Using a sample of parents and 9-to-12-year-old children, Siqueland, Kendall, and Steinberg (1996) found that independent evaluators rated parents of anxious children as more controlling than parents of non-anxious children during a task where families discussed current conflicts. In a similar study by Hudson and Rapee (2001), mother-child interaction was examined when the child was asked to solve several challenging cognitive tasks. Children included in this study were between the ages of 7 and 15; 43 were diagnosed with an anxiety disorder and 32 had no psychological diagnoses. When maternal behavior was compared across groups, mothers of anxious children displayed elevated levels of control and negativity when compared to mothers of non-clinical children.

However, only limited observational research has looked at the association between parental control and child social anxiety specifically. In an examination of the interactions of 48 father-child dyads asked to complete an origami task, Greco and Morris (2002) found that fathers of children with high levels of social anxiety were more likely to act in a controlling manner than were fathers of children with low levels of social anxiety. Similarly, in a study of 31 family triads (mothers, fathers, and children between the ages of 10 and 13), Rork and Morris (2009) found that both reported parental overprotection and observed negative commands given by mothers were positively associated with child social anxiety. 
In a recent longitudinal study, Lewis-Morrarty and colleagues (2012) found that children who showed high levels of behavioral inhibition during childhood and were exposed to maternal over-control were at increased risk for developing heightened social anxiety during adolescence when compared to behaviorally-inhibited children whose mothers showed lower levels of control.

Taken together, these studies suggest that over-controlling parenting may contribute to higher levels of child anxiety, including social anxiety. Further, the impact of parental over-control on child anxiety may extend from childhood into adolescence (e.g., Morrarty et al., 2012). In fact, a recent metaanalysis found that the relationship between parental control and child anxiety strengthened as children aged, potentially because intrusive parental involvement becomes less developmentally appropriate as children move into adolescence (van der Bruggen et al., 2008).

Although most research has examined the impact of maternal behavior on child outcomes, evidence suggests that fathers also play an important role in the development of child social anxiety (Bogels \& Phares, 2008). Early studies found that adult participants with social anxiety disorder retrospectively rated both parents as high in levels of over-control (e.g., Parker, 1979). In a study using observation of father-child interaction to examine the relationship between paternal behavior and child anxiety, Greco and Morris (2005) found that socially-anxious children were more likely than non-anxious children to have fathers that engaged in physical control during a challenging task. Further, in a recent study by Bögels, Stevens, and Majdandžić (2011), 144 children between the ages of 8 and 12 were presented with ambiguous potentially-anxiety provoking scenarios where either a mother or father was described as acting in an anxious or confident manner. Children were then asked to rate how confident they would feel in the situation. For children with high levels of social anxiety, father's described behavior had a greater influence on reported confidence level than did mother's behavior. In contrast, for children with normal or low levels of social anxiety, mother's behavior was a better predictor of children's confidence ratings than was father's behavior. 
Further, recent research suggests that fathers' behavior may be particularly important in predicting anxiety in adolescents. For example, in a study by Verhoeven, Bogels, andvan der Bruggen (2012) the impact of maternal and paternal control on offspring anxiety was examined in a sample of 179 elementary-aged students (mean age of 10 years) and a sample of 127 adolescents (mean age of 15 years). While maternal over-control predicted heightened anxiety among elementary-aged children, paternal over-control alone predicted heightened anxiety among the adolescent sample. No significant effects were found when the impact of parent and child gender was considered. This initial research indicates that fathers may play a specific role in the development of social anxiety and that fathers' influence may become more important as children move towards adolescence. The current study will adds to this literature by examining the effect of both maternal and paternal psychological control and communication on social anxiety in an early adolescent sample.

\section{Parenting and Youth Social Competence}

In addition to influencing child social anxiety, parental warmth and control may influence children's social competence (Lollis, Ross, \& Tate, 1992). Social learning theory indicates that parentchild interactions provide an early model for child behavior as they move on to develop relationships with peers (Putallaz \& Heflin, 1990). In support of this idea, research using samples of pre-adolescent children has found similarities in the affective behavior of parents during interactions with their children and children's affect during peer play. For example, Putallaz (1987) found that in a sample of first-graders, child agreeability during an interaction with a peer mirrored mother's agreeability during parent-child interaction. Similarly, Isley, O’Neil, Clatfelter, \& Parke (1999) found that kindergarten children's high positive affect mediated the relationship between parent high positive affect during play and children's ratings of high social competence by teachers and peers.

Research concerning parents and pre-adolescents has also found similarities between aspects of parent-child communication and children's peer interactions. In a comparison of the parent-child and 
child-peer conversations of children aged two to six, parents of popular children were found to show better turn-taking and more contingent responding during interactions than parents of socially rejected children, who were more likely to speak for extended periods, interrupt the child, or respond noncontingently (Black \& Logan, 1995). Children's peer interactions paralleled their parent's conversational styles, with popular children showing greater reciprocity in conversation than rejected children. In an examination of a specific aspect of communication, attempts to influence a social partner, Kochanska (1992) similarly found parallels between parent and child behaviors. Specifically, mothers who used negative control in their attempts to influence five-year-old children were more likely to have children who were aggressive with peers, whereas mothers who gently guided children were more likely to have children who had less coercive and more prosocial peer interactions.

Limited research has looked at the effect of parenting variables on early adolescents' social competence and friendship quality. Boling, Barry, Kotchick, and Lowry (2011) used a sample of 113 seventh- and eighth-grade students to examine associations between adolescents' attachment to mothers and fathers, supportiveness of the school context, and adolescents' perceived interpersonal skills and friendship quality. While quality of maternal attachment predicted adolescents' social competence directly, quality of paternal attachment only predicted social competence when the supportiveness of the school environment was also considered. Additionally, adolescents' perceived social competence was found to positively relate to friendship quality. In a study using a sample of 63 children between the ages of 7 and 12 and their parents, Festa and Ginsburg (2011) found that higher levels of parental anxiety, over-control, and rejection were associated with higher levels of child social anxiety. In turn, child social anxiety was negatively associated with peer social acceptance and friends' level of validation and support.

The current study extended previous work done regarding the relationship of parenting, social anxiety, and adolescent social adjustment by having girls aged 12 to 14 and both their male and female parents complete questionnaire measures of parent communication, parent autonomy-granting, parent 
psychological control, adolescent interpersonal skill, and adolescent friendship quality. A sample of 67 fathers, mothers, and daughters answered these questionnaires using an online data-collection system. Hypotheses tested included that lower levels of parent autonomy granting and communication, higher levels of parent psychological control, and lower levels of adolescent interpersonal skill are related to lower adolescent friendship quality. In addition, the hypothesis that social anxiety mediates the relationship between parent psychological control and adolescent friendship quality also was examined. Another model, that adolescent interpersonal skill mediates the relationship between parent communication and adolescent friendship quality, also was tested.

\section{Statement of the Problem}

In early adolescence, the basis of friendship shifts from the ability to be an enjoyable play partner to the ability to use a variety of complex interpersonal skills such as appropriate self-disclosure, provision of emotional support, and conflict resolution (Berndt, 1982; Buhrmester, 1990; Selman, 1981; Sullivan, 1953). A number of research studies have found an association between high levels of social anxiety and lower-quality friendships during adolescence (La Greca \& Harrison, 2005; La Greca \& Lopex, 1998; Starr \& Davila, 2008). Also, theory and research have indicated that socially-anxious adults show a selfprotective communication style which may negatively impact the quality of their close relationships (Arroyo \& Harwood, 2011; Cuming \& Rapee, 2011; Wenzel et al., 2005).

From a developmental perspective, adults' interpersonal skills are shaped during social interactions earlier in the lifespan. It follows that the self-protective communication style characteristic of socially-anxious adults is the result of social experiences during childhood and adolescence (Caspi, Elder, $\&$ Bem, 1988). As early adolescence has been identified as a transition point when rapid gains in interpersonal abilities are necessary for high-quality friendships, it may also be a period of high risk for socially-anxious children, who often show social skills deficits from an early age (Berndt, 1982; Spence et al., 1998; Rubin et al., 1984). However, only limited research has looked at the relationship between 
social anxiety, interpersonal skills, and friendship quality in an early adolescent population. The current study added to the literature by examining if social anxiety and interpersonal skills predict friendship quality in a group of 12-to-14-year-old early adolescent girls. If socially-anxious children are found to be behind their peers in the development of relationship skills during early adolescence, this time point may be an important period for intervention. As limited or poor quality friendships have been shown to increase risk for depression and isolation that continues into adulthood, treatments targeting interpersonal skill development at this critical period may be able to prevent long-term suffering (Bagwell et al., 1998; Buck \& Dix, 2012).

Research also has consistently indicated an association between parenting and children's anxiety (for a review see McLeod et al., 2007). However, less work has focused on how parental behavior may specifically impact children's social anxiety (for exceptions see Greco \& Morris, 2002; Rork \& Morris, 2009), or how parenting impacts social anxiety in an early adolescent population. Further, most research to date has focused on the effect of mother's behavior on children's social anxiety, while emerging evidence indicates that fathers have an equally important influence on child outcomes (for a review see Bogels \& Phares, 2008). The current study addressed these deficits by examining the impact of both maternal and paternal behavior on social anxiety in early-adolescent females.

Parenting has been implicated in children's development of interpersonal competence (Putallaz, 1987; Black \& Logan, 1985). However, most research has used samples of pre-school or school age children to examine this relationship. Further, the impact of parenting on children's general social competence, rather than their specific interpersonal skills within relationships, has typically been tested. This study adds to the literature by assessing the relationship between parental control and autonomy granting, adolescents' social skills within the context of friendships, and adolescent friendship quality.

\section{Hypotheses}


1. Lower levels of adolescent friendship quality are associated with the following variables: (a) lower levels of parent autonomy-granting, (b) lower levels of parent-adolescent communication, (c) higher levels of parent psychological control, (d) higher levels of adolescent social anxiety, and (e) lower levels of adolescent interpersonal skill. In turn, higher levels of adolescent interpersonal skill are associated with (a) higher levels of parent autonomy-granting, (b) higher levels of parent-adolescent communication, (c) lower levels of parent psychological control, (d) lower levels of adolescent social anxiety, and (e) higher levels of adolescent interpersonal skill

2. Adolescent social anxiety partially mediates the relationship between parental psychological control and adolescent friendship quality.

3. Adolescent interpersonal skill partially mediates the relationship between parent communication and adolescent friendship quality.

\section{Method}

\section{Participants}

Family groups comprised of a male parent, a female parent, and an adolescent daughter between the ages of 12 and 14 were recruited to complete online questionnaires for the current study. To participate in the study, caregivers were required to have lived at least part-time with the daughter for the past two years. Caregivers were not required to be biologically related to the daughter or required to be in a current relationship with each other. All female caregivers participating in the study were reported to be biological mothers. Male caregivers included two stepfathers and 65 biological fathers.

Recruitment was conducted by placing an advertisement describing the study and providing the researchers' contact information on online bulletin boards (e.g., craigslist, parenting websites) or on email list servs focused on parents. Parents or caregivers interested in study participation contacted the researcher via telephone or email. The researcher sent interested parents an email containing a link to the Survey Monkey web site, where parents completed consent for their own and their child's participation 
and then completed questionnaires online. Separate emails with links to consent forms and questionnaires were sent to each parent. Once a parent had provided consent for their child's participation, an email with a link to the Survey Monkey web site was sent to the email address provided for the child. Daughters completed an assent form for participation and then completed questionnaires online. Once all three family members had completed their questionnaires, they were sent an online gift card with a value of $\$ 50.00$.

One hundred and five family triads completed the online questionnaires. Examination of responses showed that nine triads reported having a daughter outside the 12-to-14-year-old age range. Data from these families were excluded from further analyses. Twenty-eight family triads were excluded because one or more member responded "choose not to respond" to $10 \%$ or more of total questions. After these exclusions, the final sample was composed of 67 male and female caregivers and daughters.

Chi-square analyses were used to examine potential differences in demographic variables between participants that were excluded from analyses due to missing data and participants that were included in analyses. Participants that had chosen "choose not to respond" for a specific demographic item were excluded from analyses including that item. Chi-square showed that the distribution of child race did not differ significantly between included and excluded participants, $X^{2}(3, \mathrm{~N}=83)=5.65, p=.13$. Similarly, chi-square analyses showed that no significant differences in racial distribution were present for included and excluded fathers, $X^{2}(3, \mathrm{~N}=70)=6.16, p=.10$, and mothers, $X^{2}(4, \mathrm{~N}=78)=8.09, p=.09$. In addition, chi-square analyses showed no significant differences in the ethnicity of included and excluded children, $X^{2}(1, \mathrm{~N}=88)=2.96, p=.09$, mothers, $X^{2}(1, \mathrm{~N}=85)=1.82, p=.18$, and fathers, $X^{2}(1, \mathrm{~N}=71)=1.77$, $p=.18$. Chi-square analyses showed no significant differences in the educational attainment of included and excluded mothers, $X^{2}(2, \mathrm{~N}=84)=1.49, p=.48$, and fathers, $X^{2}(3, \mathrm{~N}=72)=1.72, p=.63$.

The adolescent sample included 27 twelve-year-olds, 21 thirteen-year-olds, and 19 fourteen-yearolds. Specific information about participant demographics can be found in Table 1. Approximately $60 \% \mathrm{t}$ 
of participants, both adolescents and their parents, identified as White or Caucasian and approximately 20 to $30 \%$ identified as African-American. The remaining participants identified as another race or multiracial Race was not reported for two adolescents. The majority of the sample identified as non-Hispanic. Parents generally reported a high level of education, with most having obtained college or graduate degrees. Sixteen mothers did not report their age. The remaining 51 reported ages ranging from 30 to 53 $(M=41.10, S D=6.59)$. Eighteen fathers did not report their age. The remaining 49 reported ages ranging from 34 to $58(M=44.04, S D=6.74)$.

\section{Measures}

Demographic Questionnaire. Parents completed a demographic questionnaire where they provided information about their age, gender, race, ethnicity, level of education, and occupation (see Appendix A). They identified their relationship to the child (biological parent, step-parent, etc.) and their child's race and ethnicity. Parents also provided their spouse or partner's race and ethnicity.

Adolescent Interpersonal Competence Questionnaire (AICQ; Buhrmester, 1990). The AICQ was the product of an adaptation of the original adult Interpersonal Competence Questionnaire for adolescents (Buhmester, 1990). Adolescents completed this measure regarding their own social competence. This AICQ includes 40 items assessing five domains of competence in close relationships: self-disclosure, provision of emotional support, management of conflicts, negative assertion, and initiation of contacts. Items consist of statements describing behaviors that may have to be performed in the context of a friendship and are rated on a 5-point Likert-type scale with 1 indicating "Poor at this. Would be so uncomfortable and unable to handle this situation that it would be avoided if possible" and 5 indicating "EXTREMELY good at this. Would feel very comfortable and could handle the situation very well."

Scoring of subscales can be done by averaging the scores for each item on a subscale. A total score can also be obtained by calculating the average score of all subscales (e.g., McFadden, 2009). Initial research demonstrated that the AICQ has good internal consistency with all subscales having Cronbach's alphas 
greater than 0.90 (Buhrmester, 1990) and later studies have also obtained alphas of 0.95 for self-report on the AICQ (McFadden, 2009). Further, the AICQ has shown adequate test-retest reliability, with $r=0.72$ over two years; $r=0.44$ over four years; and $r=0.43$ over 6 years (Buhrmester, 2002).

Friendship Quality Questionnaire. The Friendship Quality Questionnaire (FQQ; Parker \& Asher, 1993) is a 40-item self-report measure designed to assess both positive and negative aspects of children's friendships. Adolescents read statements and rate how well they describe their friendship on a 5-point Likert-type scale ranging from "not at all true" to "really true." Results from the FQQ can be divided into six subscales including validation and caring, conflict and betrayal, companionship and recreation, help and guidance, intimate exchange, and conflict resolution. The FQQ can yield either a total friendship quality score (the conflict and betrayal scale is reverse scored and added to the other subscales) or separate negative friendship quality and positive friendship quality scores. Research using samples of early adolescent children has demonstrated that the FQQ has good internal consistency (e.g., Buck \& Dix, 2012; Baker \& Hudson, 2013; Tillfors, Persson, Willén, \& Burk, 2012). Also, previous work has found FQQ scores to be moderately correlated with variables related to the hypotheses being tested in the current study. The FQQ has been found to distinguish between the relationships of children with high and low levels of social anxiety (Festa \& Ginsburg, 2011; Fordham \& Stevenson-Hinde, 1999; Greco \& Morris, 2005; Rubin et al., 2006). Further, FQQ scores have been inversely related to child behavioral inhibition (Buck \& Dix, 2012). In the current study, participants were asked to rate their relationship with their closest same-sex friend in order to maintain consistency. A total FQQ score consisting of the summed mean subscale scores were used. Separate positive and negative friendship quality scores were not used as no particular effect of social anxiety on negative behaviors within friendships is expected.

Psychological Control Scale (PCS; Barber, 1996). The PCS is an 8-item self-report questionnaire designed to be completed by adolescents to provide a measure of the level of parents' psychological control (Barber, 1996). Adolescents are asked to rate how well various statements describe 
their mother or father on a 3-point Likert-type scale ranging from 1 (not at all like him or her) to 3 (a lot like him or her). Items included tap aspects of psychological control including attempting to change the adolescent's thoughts or emotions, using withdrawal of affection to control adolescent behavior, and not listening to the adolescent.

In an initial study using a sample of approximately 1800 ethnically-diverse children and adolescents, Barber (1996) found the PCS to have good internal consistency, with Cronbach's alphas ranging from 0.72 to 0.85 for reports of mothers and 0.74 to 0.86 for reports of fathers. Further, high levels of psychological control on the PCS were found to be associated with higher levels of adolescent depressive symptoms. In a later study involving 750 adolescents between the ages of 11 and 17, the PCS was found to have good internal consistency (Cronbach's alpha $=0.88)$ and to be associated with higher levels of adolescent depression, lower levels of self-esteem, and lower levels of adolescent interpersonal social initiative (Barber \& Erickson, 2001). Consistent with previous research, the current study will use the mean score of all items.

Adolescents self-report is an appropriate and important source of information about the experience of parent psychological control for several reasons. Parents may be unlikely to report their own negative behaviors; further, the subjective experience of feeling controlled, manipulated, or coerced by parents may be equally important as more objective measurements of these behaviors (Barber et al., 2011). In the current study, adolescents completed the PCS for mothers and fathers separately.

Parent-Child Relationship Inventory (PCRI; Gerard, 2000). The PCRI is a 78-item selfreport questionnaire designed to be completed by parents about dimensions of their relationship with their child. When completing the questionnaire, the parent rates each statement on a 4-point Likert-type scale ranging from 1, Strongly Agree, to 4, Strongly Disagree. The PCRI contains seven subscales measuring different aspects of parenting plus two validity scales, one measuring the tendency to respond in a socially-desirable manner and one measuring inconsistent responding. The main seven subscales of the 
PCRI include (a) perceived level of social and emotional support received by the parent, (b) satisfaction with parenting, (c) parent's level of involvement with the child, (d) parent's ability to communicate with the child, (d) parent's ability to set limits with the child, (e) parent's level of autonomy granting, and (f) parent's perception of gender roles.

For the purposes of the current study, the 9-item communication subscale, which measures how open the child is in talking with the parent and the parent's ability to relate to the child, and the 10 -item autonomy subscale, which measures the parent's willingness and ability to promote the child's independence, were used. These subscales have shown good internal consistency, with Cronbach's alpha equivalent to 0.82 for the communication scale and Cronbrach's alpha equivalent to 0.78 for the autonomy scale (Gerard, 2000). These two scales were selected because the results of prior research indicate that parents' communication skills with their children directly influence children's social competence (e.g., Black \& Logan, 1995; Putallaz, 1987). Further, autonomy-granting has been conceptualized as a distinct construct from parental psychological control; therefore the addition of the autonomy scale should add explanatory power beyond adolescent report on the PCS (e.g., Silk et al., 2003). While psychological control is thought of as covert attempts to manipulate the child's emotions and behavior, autonomy-granting is thought of as encouragement of the child's independent decision making and self-determination. Further, parental autonomy-granting has been shown to relate to higher levels of social competence in adolescence (Silk et al., 2003). In the current study, both mothers and fathers will complete the communication and autonomy subscales of the PCRI.

Social Phobia and Anxiety Inventory for Children (SPAI-C). The SPAI-C (Beidel, Turner, \& Morris, $1995 ; 1998)$ is a 26 -item self-report questionnaire designed to assess social anxiety in children ages 8 to 14. Children are asked to rate how much statements describing thoughts, feelings, and behaviors describe their own experience on a Likert-type scale ranging from 0 , never or hardly ever, to 2 , most of the time or always. An initial investigation (Beidel et al., 1995) showed that the SPAI-C had high 
internal consistency (Cronbach's $\alpha=0.95)$, high test-retest reliability over two weeks $(r=0.86)$, and moderate test-retest reliability over 10 months $(r=0.63)$. Further, the convergent validity of the SPAI-C has been demonstrated through correlation between higher SPAI-C scores and greater number of distressing social experiences as recorded in a daily diary (Beidel, Turner, \& Fink, 1996). The SPAI-C has also shown external validity through correlation of scores with parent report of child social anxiety and observer ratings of child social skill (Beidel, Turner, Hamlin, \& Morris, 2000). The discriminant validity of the SPAI-C has been shown through the use of scores to identify children with SAD versus children with other anxiety disorders (Beidel et al., 2000) and children with SAD versus children with externalizing disorders or no disorder (Beidel et al., 1996).

\section{Procedures}

Using Survey Monkey, both male and female parent participants completed the Demographic Questionnaire (see Appendix A) and the PCRI communication and autonomy subscales. Adolescents completed the SPAI-C, the PCS (mother and father versions), the AICQ, and the FQQ. All questions were completed by having the respondent select one of a number of multiple-choice boxes. Respondents could decline to answer any question by selecting a "choose not to respond" button.

\section{Results}

Data Preparation. Individual questionnaires that were missing $20 \%$ or more of total responses were excluded from analyses. Application of this criterion led to the removal of one AICQ and one paternal PCS. No mother-report or father-report scales were excluded due to missing data. Descriptive statistics for each variable can be found in Table 2.

Tests of Normality of Variable Distributions. The normality of distributions for questionnaire measures was examined using the Shapiro-Wilk $W$ test (Shapiro \& Wilk, 1965) as well as examination of skewness, kurtosis, and the presence of outliers. Following the recommendation of Tabachnick and Fidell (2007), skewnesss and kurtosis with z-scores of less than positive or negative 3.29 were considered to be 
within the limits of a normal distribution. Father report on the PCRI autonomy scale was normally distributed, $S W=0.97, d f=67, p=.10$. The distribution of father report on PCRI communication scale was significantly different from normal, $S W=0.91, d f=67, p=.00$. However, z-scores for skewness, 2.53, and kurtosis, -0.76 , were within normal limits. Father PCRI autonomy and communication scores were not transformed for analyses.

The distribution of maternal report on the PCRI autonomy scale did not differ significantly from normal, $S W=0.97, d f=67, p=.06$. The distribution of the maternal PCRI communication scale varied significantly from normal, $S W=0.90, d f=67, p=.00$. However, z-scores for skewness, 1.77 , and kurtosis, -1.92, were within normal limits. Mother PCRI autonomy and communication scores were not transformed for analyses.

The normality of the distributions of adolescent-report variables was also examined using the Shapiro-Wilks $W$ test. The FQQ score distribution was significantly different from a normal distribution, $S W=0.94, d f=67, p=.00$. Examination of z-scores for skewness, -1.88 , and kurtosis, -1.22 , for the FQQ showed that they were within normal limits. The distribution of the SPAI-C data also varied significantly from a normal distribution, $S W=0.93, d f=67, p=.00$. However, z-scores for the skewnesss, 2.96, and kurtosis, 0.79 , of the SPAI-C were within normal limits. The AICQ score distribution did not differ significantly from a normal distribution, $S W=0.97, d f=66, p=.10$.

The distribution of the maternal PCS was significantly different from a normal distribution, $S W=$ $0.78, d f=67, p=.00$. Further, the z-score for skewness of the maternal PCS, 4.81, was above the acceptable limit. The z-score for the kurtosis of this variable's distribution, 2.23, was within normal limits. The distribution of the paternal PCS also varied significantly from a normal distribution, $S W=$ $0.76, d f=66, p=.00$. Examination of the z-score for skewness, 5.10 , showed that it was outside an acceptable limit. However, the z-score for kurtosis, 2.10, was within normal limits. The Box-Cox transformation (Box \& Cox, 1964; Osborne, 2010) with a lambda of -6 was used to transform the 
maternal PCS data. While the Shapiro-Wilk test showed that the distribution of this variable still differed significantly from a normal distribution after this transformation, $S W=0.79, d f=67, p=.00$, skewness was significantly reduced $(z=0.06)$ and kurtosis remained within normal limits $(z=3.08)$ A Box-Cox transformation with a lambda of -3.10 was used to transform the paternal PCS data. While the ShapiroWilk test showed that the distribution of the paternal PCS still differed significantly from a normal distribution after this transformation, $S W=0.88, d f=66, p=.00$, skewness was significantly reduced $(z$ $=0.06)$ and kurtosis remained within normal limits $(z=-2.42)$.

Influence of Demographic Factors. Differences in mother and father scores on the PCRI autonomy and communication scales and PCS were examined using independent samples t-tests. No significant difference was found between mothers' $(M=23.75, S D=5.64)$ and fathers' $(M=24.70, S D=5.26)$ level of autonomy granting, $t(132)=1.01, p=.31$. In addition, no significant difference was found between mothers' $(M=19.33, S D=8.19)$ and fathers' $(M=17.91, S D=6.64)$ quality of communication with daughters, $t(126.61)=-1.10, p=.27$. An independent samples t-test comparing mothers' and fathers' scores on the PCS showed that adolescents perceived fathers as significantly more psychologically controlling than mothers, $t(103.07)=2.44, p=.02$. While fathers received a mean score of 1.41 $(\mathrm{SD}=0.51)$ on the untransformed PCS, mothers received a mean score of $1.23(\mathrm{SD}=0.29)$. As planned, father and mother scores were entered into separate models.

As the study sample included some racial diversity, differences in study variables by race were examined using independent-samples t-tests (See Table 3). Due to the small sample size, participants were grouped in the categories of white and non-white for these analyses. The two adolescents whose race was not reported were not included. Differences in white versus non-white participants were found for the PCRI mother and father autonomy-granting scales, with white parents reporting significantly higher levels of autonomy granting when compared to non-white parents. This finding is consistent with previous work indicating that parents who are members of minority groups may grant children less 
autonomy when compared to parents who are members of the majority group, potentially due to greater perceived environmental dangers (e.g., Caughy, Nettles, O'Campo, \& Lohrfink, 2006). Due to this difference between white and non-white participants, race was included as a covariate in relevant analyses.

Preliminary Analyses. Pearson bivariate correlations were calculated between each variable (see Table 4). Maternal and paternal autonomy granting scores on the PCRI showed a significant positive relation. Maternal autonomy granting and maternal communication on the PCRI were negatively associated. Higher levels of maternal communication were associated with lower levels of perceived maternal control on the PCS, better adolescent interpersonal skills on the AICQ, better adolescent friendship quality on the FQQ, and lower adolescent social anxiety on the SPAI-C. No significant association was found between father scores on the PCRI autonomy-granting and communication subscales and other variables. Mother and father psychological control as measured by the PCS showed a significant positive relation. Maternal psychological control was associated with higher adolescent social anxiety and lower adolescent interpersonal skill and friendship quality. No significant associations between father psychological control and adolescent outcomes were present. Adolescent interpersonal skill showed a significant positive relation to adolescent friendship quality and a significant negative relation to adolescent social anxiety.

Primary Analyses. The first hypothesis, that parenting, adolescent social anxiety, and adolescent interpersonal skill predict adolescent friendship quality was tested using stepwise multiple regression. Mother and father variables were entered into separate models. The following were entered as predictors in a forced entry multiple regression with FQQ score as the outcome variable: maternal PCRI autonomy score, maternal PCRI communication score, adolescent ratings of mothers on the PCS, AICQ score, and SPAIC score. Race (white or non-white) was entered into the first block of the regression and other predictors were entered in a second block. Race alone was not a significant predictor of friendship quality, 
$R^{2}=0.05, F(1,62)=3.16, p=.08$. The total model containing race, maternal parenting variables, adolescent interpersonal skill, and adolescent social anxiety explained a significant proportion of variance in friendship quality, $R^{2}=0.23, F(6,57)=2.84, p=.02$. However, when individual predictors were examined, only maternal ratings on the PCS significantly predicted friendship quality $(\beta=-0.36, p=.02)$. . Variance inflation factors for this regression were within acceptable limits (0.71-2.55).

A second forced-entry multiple regression was run with FQQ as the dependent variable and paternal PCRI autonomy score, paternal PCRI communication score, adolescents' ratings of fathers on the PCS, AICQ score, and SPAIC score as predictors. Race, white versus non-white, was entered as a predictor in the first block and all other predictors were entered in a second block. Race alone was not found to account for a significant amount of variance, $R^{2}=0.04, F(1,61)=2.52, p=.12$. The total model including all other predictors was not significant, $R^{2}=0.14, F(6,56)=1.47, p=.20$. Variance inflation factors for this regression were within acceptable limits (1.00-2.43).

The second hypothesis, that adolescent social anxiety mediates the relationship between parental psychological control and adolescent friendship quality was first tested using Baron and Kenny's (1986) causal steps approach. Two models were tested, one using maternal psychological control and one using paternal psychological control as the predictor. Figure 1 illustrates this mediational model using maternal PCS scores. A simple regression with maternal PCS score as the predictor and FQQ score as the outcome was significant, $R^{2}=0.15, F(1,65)=11.00, p=.001$. A second regression with maternal PCS score as the predictor and SPAI-C as the outcome score was also significant, $R^{2}=0.30, F(1,65)=27.76, p=.00$. However, a third regression with SPAI-C score as the predictor and FQQ as the outcome variable was not significant, $R^{2}=0.05, F(1,65)=3.13, p=.08$. The lack of a relationship between the SPAI-C and FQQ precludes a mediational model using the causal steps approach (Baron \& Kenny, 1986).

The mediation of paternal psychological control and adolescent friendship quality by adolescent social anxiety was also tested using the causal steps approach. A regression with paternal PCS scores 
entered as a predictor was not found to account for a significant amount of variance in SPAIC scores, $R^{2}=$ $0.04, F(1,64)=2.40, p=.13$. Paternal PCS scores also did not significantly predict FQQ scores, $R^{2}=$ $0.00, F(1,64)=0.06, p=.81$. Also, as seen in the model using maternal PCS scores, SPAI-C scores did not predict FQQ scores, $R^{2}=0.00, F(1,65)=3.13, p=.08$. Therefore, the mediational model was not supported. This model is further illustrated in Figure 2.

Hypothesis two was also tested using the Preacher and Hayes (2008) mediation macro. This method may be superior to the causal steps method in detecting mediation as it does not assume a normal distribution of variables and estimates indirect effects through the use of bootstrap confidence intervals that are bias-corrected (Preacher \& Hayes, 2008). In the current analyses, 5,000 boot-strap resamples and $95 \%$ confidence intervals were used. Use of bootstrapping confirmed the previous analyses, showing that SPAIC scores did not mediate the relationship between maternal PCS scores and FQQ scores as 95\% confidence intervals for the indirect effect ranged from -7.97 to 8.32. Similarly, use of the Preacher and Hayes (2008) bootstrapping method confirmed that SPAIC scores did not mediate the relationship between paternal PCS and FQQ scores as 95\% confidence intervals for the indirect effect ranged from 4.87 to 0.17 .

Hypothesis three, that adolescents' interpersonal skill (as measured using the AICQ) mediates the relationship between parental communication (as measured by the PCRI) and adolescent friendship quality (as measured using the FQQ) was first tested using the causal steps model (Baron \& Kenny, 1986). The influence of maternal (see Figure 3) and paternal communication (see Figure 4) were tested separately. Maternal communication significantly predicted adolescent interpersonal skill, $R^{2}=0.10, F(1$, $64)=6.85, p=.01$. Maternal communication scores also significantly predicted adolescent friendship quality, $R^{2}=0.06, F(1,65)=4.11, p=.05$. Finally, adolescent interpersonal skill significantly predicted adolescent friendship quality, $R^{2}=0.06, F(1,64)=4.01, p=.05$. In a multiple regression, maternal communication and adolescent interpersonal skill accounted for approximately $9 \%$ of the total variance in 
adolescent friendship quality, $R^{2}=0.09, F(2,63)=3.05, p=.05$. Neither maternal communication $(\beta=$ $0.18, p=.16)$ nor adolescent interpersonal skill $(\beta=0.19, p=.15)$ were significant predictors of friendship quality when entered into the multiple regression; therefore, mediation of the relationship between maternal communication and adolescent friendship quality by adolescent interpersonal skill was not supported. Similarly, use of the Preacher and Hayes (2008) method confirmed that AICQ scores did not mediate the relation between maternal communication and adolescent friendship quality as $95 \%$ confidence intervals for the indirect effect ranged from -0.01 to 0.08 .

This model was then tested using paternal communication as a predictor. Paternal communication did not significantly predict adolescent interpersonal skills, $R^{2}=0.03, F(1,64)=1.71, p=.20$, or adolescent friendship quality, $R^{2}=0.01, F(1,65)=0.01, p=.39$. As in the model using maternal communication, adolescent interpersonal skill significantly predicted adolescent friendship quality, $R^{2}=$ $0.06, F(1,64)=4.01, p=.05$. Use of the Preacher and Hayes (2008) method confirmed the lack of mediation in this model as $95 \%$ confidence intervals for the indirect effect ranged from -0.004 to 0.09 .

\section{Discussion}

Examination of Proposed Hypotheses. Hypothesis one, that higher levels of parent autonomygranting and communication, lower levels of parental control, lower levels of child social anxiety, and higher levels of child interpersonal skill are associated with higher levels of child friendship quality, was partially supported when maternal measures were used. However, hypothesis one was not supported when paternal measures were used. Overall, maternal communication, autonomy granting, psychological control, adolescent social anxiety, and adolescent interpersonal skill explained approximately $23 \%$ of the variance in adolescent friendship quality. When individual predictors were examined, higher levels of maternal control were significantly associated with lower levels of friendship quality. No significant associations between other predictors and adolescent friendship quality were present. 
The second hypothesis, that adolescent social anxiety mediates the relation between parental psychological control and adolescent friendship quality, was not supported when either mother or father PCS scores were used. Maternal psychological control did significantly predict adolescent friendship quality and adolescent social anxiety. However, no significant relation was found between adolescent social anxiety and friendship quality, precluding a mediational model. When father variables were examined, no relation was found between paternal psychological control and adolescent social anxiety or friendship quality. Also, as in the model using maternal variables, social anxiety was not a significant predictor of friendship quality.

The third hypothesis, that adolescent interpersonal competence mediates the relation between parent communication skills and adolescent friendship quality, was not supported when either mother or father communication were used as a predictor. When maternal variables were considered, communication was positively related to adolescent interpersonal skill level and friendship quality. In addition, a significant relation was present between adolescent interpersonal skill and friendship quality. However, a multiple regression with maternal communication and adolescent interpersonal skill as predictors and friendship quality as the outcome showed that neither predictor accounted for a significant proportion of variance when the other was included in the model. No significant associations were present when paternal communication was used as a predictor for adolescent interpersonal skill and friendship quality.

Maternal Parenting and Adolescent Outcomes. Maternal communication and psychological control showed significant associations with daughter variables including social anxiety, interpersonal skill, and friendship quality. Higher levels of maternal communication on the PCRI predicted lower levels of adolescent social anxiety, higher levels of adolescent interpersonal skill, and better adolescent friendship quality. Mothers who rate themselves highly on the PCRI communication scale endorse that they are able to read their adolescent's emotions using facial expression, are good listeners, and use 
reasoning rather than commands with their children. Using a social learning perspective, children with mothers who demonstrate these skills should then use these positive communication strategies with peers (Putallaz, 1987). This idea is supported by the positive correlations between mother communication and higher child social skill as measured by the AICQ and higher child friendship quality on the FQQ. Further, mother communication was associated with lower social anxiety, perhaps due to its association with higher adolescent social skill, which may lead to more positive peer experiences. Factors related to the adolescent should also be considered when examining the association between higher quality maternal communication and child interpersonal skills. Adolescents who are less anxious and show more positive affect may elicit more positive communication behaviors from parents when compared to adolescents with higher levels of anxiety and negative affect.

The positive association between maternal psychological control and adolescent social anxiety supports prior research linking parental psychological control with child anxiety in general (Krohne \& Hock, 1991; Siqueland et al., 1996) and child social anxiety specifically (Greco \& Morris, 2002). Bivariate correlations between individual items on the maternal PCS and the SPAI-C total score showed that higher levels of adolescent social anxiety were particularly associated with adolescents' perception that mothers tried to change their thoughts and feeling $(r=0.47, p<.01)$, changed the subject $(r=0.27, p$ $<.05)$ or interrupted them $(r=0.34, p<.01)$ during conversation, blamed them for other family members' problems $(r=0.26, p<.05)$, and were less friendly when they disagreed $(r=0.26, p<.05)$. Examination of these associations indicates that adolescents with higher social anxiety were more likely than adolescents with lower social anxiety to report a general sense that their mothers were intrusively involved in their thoughts and feelings. In addition, adolescent social anxiety appears to be associated with having punitive experiences during interactions with mothers; specifically, being ignored and interrupted. 
That maternal psychological control is displayed through aversive social interactions provides several possible explanations for the negative associations between maternal control and adolescent interpersonal skills and friendship quality. Daughters of mothers who engage in social behaviors such as interruption and ignoring may demonstrate these behaviors during interactions with peers, leading to negative social experiences which may increase anxiety. Adolescents who experience punishing interactions with mothers also may be less likely to seek out social interaction than adolescents who have a history of positive social interactions. In addition, if behaviors such as self-disclosure or assertion are punished during interactions with mothers, adolescents may be less likely to engage in these behaviors during interactions with peers.

Paternal Parenting and Adolescent Outcomes. Contrary to predictions, significant associations between father parenting variables and adolescent outcomes were not present. This lack of associations may indicate that fathers influence adolescents' anxiety and social behavior through different channels when compared with mothers. Bogels and Phares (2008) emphasize that as fathers and mothers traditionally play different roles, parenting behaviors associated with child anxiety will likely differ based on the parent's gender. For example, mothers may be more likely than fathers to provide comfort and support to the child while fathers may be more likely than mothers to provide limits and boundaries. Parents' failure to engage in behaviors associated with their gender role may be anxiety-provoking for children, especially if the other parent does not compensate.

Differences in the roles of mothers and fathers may explain, at least in part, the lack of a significant association between paternal psychological control and adolescent social anxiety. Although there was a trend towards daughters rating fathers as more psychologically controlling than mothers; paternal psychological control did not appear to have the same negative effects on adolescent outcomes when compared to maternal psychological control. If daughters typically turn to mothers, rather than fathers, for comfort and support, then maternal psychological control and the associated punitive social 
interactions may be more anxiety-provoking for adolescents than paternal psychological control. It should also be noted that while high levels of maternal psychological control were linked to lower levels of maternal communication, level of father psychological control was not associated with father communication. Therefore, it is also possible that parental psychological control alone is not as anxietyprovoking as the combination of psychological control and low levels of communication, a pattern which may be more likely to occur in mothers than fathers.

The lack of association between fathers' parenting behavior and adolescent interpersonal skill and friendship quality is consistent with some prior work suggesting that children's communication with same-sex peers is most influenced by their communication with their same-sex parent. For example, Isley and colleagues (1999) found the strongest effects of parent-expressed positive affect on children's social competence in father-son and mother-daughter dyads. When only father-daughter dyads were examined, father's affect did not impact daughters' social competence. From a learning theory perspective, social behaviors developed during interactions with a same-gender parent would be more likely to occur during interactions with a same-gender peer.

\section{Adolescent Social Anxiety, Interpersonal Skill, and Friendship Quality. Adolescent}

perception of interpersonal skill, as measured by the AICQ, showed a strong negative association with SPAIC scores, suggesting that adolescents who perceived themselves as more socially anxious also perceived themselves as having lower levels of interpersonal skill. This finding is consistent with prior work showing an association between lower adolescent interpersonal skill and social anxiety (Buhrmester, 1990; 2002; McFadden, 2009). The negative relation between the SPAI-C and AICQ also provides support for the idea that socially-anxious individuals use a self-protective communication style (e.g., Arkin et al., 1986; Cuming \& Rapee, 2010). For example, further examination of correlations between subscales of the AICQ and the SPAI-C total score found particularly strong negative associations between the SPAI-C and AICQ subscales measuring self-disclosure $(r=-0.68, p<.01)$ and 
assertion $(r=-0.72, p<.01)$. The positive correlation between the AICQ and FQQ also supports the idea that adolescents with better interpersonal skills have higher quality friendships.

Summary of Findings. In summary, the current study identified associations among parenting variables and adolescent social anxiety, interpersonal skill, and friendship quality. Higher-quality maternal communication was associated with lower levels of adolescent social anxiety, better adolescent interpersonal skills, and higher adolescent friendship quality. Perceived maternal psychological control was associated with higher adolescent social anxiety, poorer adolescent interpersonal skills, and lower adolescent friendship quality. In contrast, no significant associations were found between paternal communication or psychological control and adolescent outcomes. As expected, adolescents who reported higher levels of social anxiety also reported lower levels of interpersonal skill. In addition, adolescents who perceived themselves as more socially skilled also reported higher friendship quality. These findings supports prior questionnaire and observational research linking social anxiety with poorer-quality interpersonal interactions and friendships.

\section{Limitations}

The current study has several limitations. As questionnaire measures were used, it is important to keep in mind that variables reflect perceptions rather than actual behaviors. For example, adolescents may feel socially anxious and perceive that they have low interpersonal competence when observation of their social behavior would not support this conclusion. In addition, it is important to acknowledge that no causal relations can be inferred from the present study as the data is correlation in nature. The bidirectional nature of parent-child interactions should also be kept in mind when considering parent influences on child anxiety, as children may shape parents' behavior as much as parents shape children's behavior (Bell, 1979).

\section{Implications}


In the current study, higher quality maternal communication was associated with both lower child social anxiety and better child social skills. In contrast, higher maternal psychological control was associated with higher child social anxiety and poorer child social skills. These findings are consistent with previous research and underscore the importance of maternal parenting in early adolescent girls' social and emotional development. In addition, the associations between mothers' parenting behaviors and daughter outcomes indicate that it may be beneficial to include parents when providing intervention to early adolescents experiencing social anxiety or peer problems. The lack of associations between paternal parenting variables and adolescent outcomes in the current study indicates that more parenting behaviors may need to be examined in order to better understand the role that fathers play in children's development of social behaviors and social anxiety. The connections between adolescents' social anxiety, perceived interpersonal skill, and friendship quality are consistent with previous literature and indicate that interventions aimed at increasing adolescents' confidence during peer interactions may be beneficial in decreasing social fears and improving peer relationship quality.

\section{Future Directions}

To continue the examination of the interplay of parenting, adolescent social anxiety, adolescent interpersonal skill, and adolescent friendship quality, observational measures of parent-adolescent interaction and adolescent-friend interaction would be beneficial. The use of observational measures of parent-adolescent and adolescent-friend interactions could be used to conduct a more fine-grained analysis of similarities between parent and adolescent communication style. Information from a study such as this could be used to help shape parent-adolescent interactions that would be more conducive to positive adolescent-friend interactions. Longitudinal research using parent-child interactions at an earlier time point and adolescent-friend interactions at a later time point would be particularly useful in clarifying the influence of parents on child social skills in a dyadic context. In addition, to better understand the changes in children's relationships to parents and peers during the transition from 
childhood to adulthood, longitudinal designs involving repeated measurement of the same child or crosssectional designs involving different age groups of children would be beneficial.

Measurement of a wider variety of parenting behaviors may be necessary to tap the different ways that mothers and fathers influence child social anxiety and social skill. For example, recent research indicates that fathers' behavior during potentially threatening social situation may have more influence on children's anxiety when compared to mothers' behavior (Bogels et al., 2011). In addition, analyses that consider the interactional effects of both parents' behavior on children's social anxiety and interpersonal skills would add to research which has primarily focused on each parents' behavior independently. 


\section{References}

Adelson, J., \& Douvon, E. (1975). Adolescent friendships. In J. J. Conger (Ed.), Contemporary issues in adolescent development (pp. 277-322). New York: Harper and Row.

Alden, L. E., \& Bieling, P. (1998). Interpersonal consequences of the pursuit of safety. Behaviour Research and Therapy, 36, 53-64. doi:10.1016/S00057967(97)00072-7

Alden, L. E., \& Taylor, C. T. (2004). Interpersonal processes in social phobia. Clinical Psychology Review, 24, 857- 882. doi:10.1016/j.cpr.2004.07.006

American Psychiatric Association. (2000). Diagnostic and statistical manual of mental disorders ( $4^{\text {th }}$ ed., text rev.). Washington, DC: Author.

Arkin, R. M., Lake, E. A., \& Baumgartner, A. H. (1986). Shyness and self-presentation. In W. H. Jones, J. M. Cheek, and S. R. Briggs (Eds.), Shyness: Perspectives on research and treatment (pp. 189-203). New York: Plenum.

Arrindell, W. A., Emmelkamp, P. M.G., Monsma, A., \& Brilman, E. (1983). The role of perceived parental rearing practices in the aetiology of phobic disorders: A controlled study. British Journal of Psychiatry, 143, 183-187. doi:10.1192/bjp.143.2.183

Arrindell, W. A., Kwee, M. G. T., Methorst, G. J., Van der Ende, J., Pols, E., \& Moritz, B. J. M. (1989). Perceived parental rearing styles of agoraphobic and socially phobic inpatients. British Journal of Psychiatry, 155, 526-535. doi:10.1192/bjp.155.4.526

Arroyo, A., \& Harwood, J. (2011). Communication competence mediates the link between shyness and relational quality. Personality and Individual Differences, 50, 264-267. doi:10.1016/j.paid.2010.09.041

Bagwell, C. L., Newcomb, A. F., \& Bukowski, W. M. (1998). Preadolescent friendship and peer 
rejection as predictors of adult adjustment. Child Development, 69, 140-153.

doi:10.2307/1132076

Baker, J. R., \& Hudson, J. L. (2013). Friendship quality predicts treatment outcome in children with anxiety disorders. Behaviour Research and Therapy, 51, 31-36.

doi:10.1016/j.brat.2012.10.005

Barber, B. K. (1996). Parental psychological control: Revisiting a neglected construct. Child Development, 67, 3296-3319. doi:10.2307/1131780

Barber, B. K., \& Erickson, L. D. (2001). Adolescent social initiative: Antecedents in the ecology of social connections. Journal of Adolescent Research, 16, 326-354. doi:10.1177/0743558401164003

Barber, B. K., Xia, M., Olsen, J. A., McNeely, C. A., \& Bose, K. (2012). Feeling disrespected by parents: Refining the measurement and understanding of psychological control. Journal of Adolescence, 35, 273-287. doi:10.1016/j.adolescence.2011.10.010

Baron, R. M., \& Kenny, D. A. (1986). The moderator-mediator variable distinction in social psychological research: Conceptual, strategic, and statistical considerations. Journal of Personality and Social Psychology, 51, 1173-1182. doi:10.1037/0022-3514.51.6.1173

Beidel, D. C., Turner, S. M., \& Fink, C. M. (1996). Assessment of childhood social phobia: Construct, convergent, and discriminative validity of the social phobia and anxiety inventory for children (SPAI-C). Psychological Assessment, 8, 235-240. doi:10.1037/10403590.8.3.235

Beidel, D. C., Turner, S. M., Hamlin, K., \& Morris, T. L. (2000). The social phobia and anxiety inventory for children (SPAI-C): External and discriminative validity. Behavior Therapy, 31, 75-87. doi:10.1016/S0005-7894(00)80005-2

Beidel, D. C., Turner, S. M., \& Morris, T. L. (1995). A new inventory to assess childhood social anxiety and phobia: The social phobia and anxiety inventory for children. 
Psychological Assessment, 7, 73-79. doi:10.1037/1040-3590.7.1.73

Beidel, D. C., Turner, S. M., \& Morris, T. L. (1998). Social phobia and anxiety inventory for children. North Tonawanda, NY: Multi-Health Systems.

Beidel, D. C., Turner, S. M., Young, B. J., Ammerman, R. T., Sallee, F. R., \& Crosby, L. (2007). Psychopathology of adolescent social phobia. Journal of Psychopathology and Behavioral Assessment, 29, 47-54. doi:10.1007/s10862-006-9021-1

Bell, R. Q. (1979). Parent, child, and reciprocal influences. American Psychologist, 34, 821-826.

Berndt, T. J. (1982). The features and effects of friendship in early adolescence. Child Development, 53, 1447-1460. doi:10.2307/1130071

Bierman, K. (2004). The developmental significance of peer relations. In K. Bierman (Ed.), Peer rejection: Developmental processes and intervention strategies (pp. 3-15). New York: Guildford.

Biggs, B. K., Vernberg, E. M., \& Wu, Y. P. (2012). Social anxiety and adolescents' friendships: The role of social withdrawal. Journal of Early Adolescence, 32, 802-823. doi: $10.1177 / 0272431611426145$

Black, B., \& Logan, A. (1995). Links between communication patterns in mother-child, fatherchild, and child-peer interactions and children's social status. Child Development, 66, 255-271. doi: $10.2307 / 1131204$

Bögels, S., \& Phares, V. (2008). Fathers' role in the etiology, prevention and treatment of child anxiety: A review and new model. Clinical Psychology Review, 28, 539-558. doi:10.1016/j.cpr.2007.07.011

Bögels, S., Stevens, J., \& Majdandžić, M. (2011). Parenting and social anxiety: Fathers’ versus mothers' influence on their children's anxiety in ambiguous social situations. Journal of 
Child Psychology and Psychiatry, 52, 599-606. doi:10.1111/j.1469-

7610.2010.02345.x

Box, G. E. P., \& Cox, D. R. (1964). An analysis of transformations. Journal of the Royal Statistical Society, 26, 211-234.

Boling, M. W., Barry, C., Kotchick, B. A., \& Lowry, J. (2011). Relations among early adolescents' parent-adolescent attachment, perceived social competence, and friendship quality. Psychological Reports, 109, 819-841. doi:10.2466/02.07.09.21.PR0.109.6.819-841

Buck, K., \& Dix, T. (2012). Can developmental changes in inhibition and peer relationships explain why depressive symptoms increase in early adolescence? Journal of Youth and Adolescence, 41, 403-413. doi:10.1007/s10964-011-9651-9

Buhrmester, D. (1990). Intimacy of friendship, interpersonal competence, and adjustment during preadolescence and adolescence. Child Development, 61, 1101-1111. doi: $10.2307 / 1130878$

Buhrmester, D. (April, 2002). The development of interpersonal competence during adolescence: A six-year longitudinal study. Poster presented at the Society for Research on Adolescence Conference, New Orleans, LA.

Buhrmester, D., \& Furman, W. (1987). The development of companionship and intimacy. Child Development, 58, 1101-1113. doi:10.2307/1130550

Buhrmester, D., Furman, W., Wittenberg, M. T., \& Reis, H. T. (1988). Five domains of interpersonal competence in peer relationships. Journal of Personality and Social Psychology, 55, 991-1008. doi:10.1037/0022-3514.55.6.991

Caspi, A., Elder, G. H., \& Bem, D. J. (1988). Moving away from the world: Life-course patterns of shy children. Developmental Psychology, 24, 824-831. doi:10.1037/00121649.24.6.824 
Caughy, M., Nettles, S., O' Campo, P. J., \& Lohrfink, K. (2006). Neighborhood matters: Racial socialization of African American children. Child Development, 77, 1220-1236. doi:10.1111/j.1467-8624.2006.00930.x

Clark, K., \& Ladd, G. (2000). Connectedness and autonomy support in parent-child relationships: Links to children's socioemotional orientation and peer relationships. Developmental Psychology, 36, 485-498. doi:10.1037/0012-1649.36.4.485

Compton, S. N., Nelson, A. H., \& March, J. S. (2000). Social phobia and separation anxiety symptoms in community and clinical samples of children and adolescents. Journal of the American Academy of Child \& Adolescent Psychiatry, 39, 1040-1046. doi:10.1097/00004583-200008000-00020

Cook, E. C., \& Fletcher, A. C. (2012). A process model of parenting and adolescents' friendship competence. Social Development, 21, 461-281. doi:10.1111/j.1467-9507.2011.00642.

Cooper, C. R., \& Cooper, R. G. (1992). Links between adolescents' relationships with their parents and peers: Models, evidence, and mechanisms. In R. D. Parke \& G. W. Ladd (Eds.), Family-peer relationships: Modes of linkage (pp. 135-158). Hillsdale, NJ: Lawrence Erlbaum.

Crawford, A., \& Manassis, K. (2011). Anxiety, social skills, friendship quality, and peer victimization: An integrated model .Journal of Anxiety Disorders, 25, 924-931. doi:10.1016/j.janxdis.2011.05.005

Cuming, S., \& Rapee, R. M. (2010). Social anxiety and self-protective communication style in close relationships. Behaviour Research and Therapy, 48, 87-96. doi:10.1016/j.brat.2009.09.010

de Vente, W., Majdandžić, M., Colonnesi, C., \& Bögels, S. M. (2011). Intergenerational transmission of social anxiety: The role of paternal and maternal fear of negative child evaluation and parenting behavior. Journal of Experimental Psychopathology, 2, 509- 
530.

Dumas, J. E., \& LaFreniere, P. J. (1993). Mother-child relationships as sources of support or stress: A comparison of competent, average, aggressive, and anxious dyads. Child Development, 64, 1732-1754. doi:10.2307/1131466

Dumas, J. E., Serketich, W. J. \& LaFreniere, P. J. (1995). “Balance of power:” A transactional analysis of control in mother-child dyads involving socially competent, aggressive, and anxious children. Journal of Abnormal Psychology, 104, 104-113. doi:10.1037/0021-843X.104.1.104

Engels, R. E., Deković, M., \& Meeus, W. (2002). Parenting practices, social skills and peer relationships in adolescence. Social Behavior and Personality, 30, 3-18. doi:10.2224/sbp.2002.30.1.3

Engels, R. E., Finkenauer, C., Meeus, W., \& Deković, M. (2001). Parental attachment and adolescents' emotional adjustment: The associations with social skills and relational competence. Journal of Counseling Psychology, 48, 428-439. doi:10.1037/0022-0167.48.4.428

Essau, C. A., Conradt, J., \& Petermann, F. (1999). Frequency and comorbidity of social phobia and social fears in adolescents. Behaviour Research and Therapy, 37, 831-843. doi:10.1016/S0005-7967(98)00179-X

Faul, F., Erdfelder, E., Buchner, A., \& Lang, A.G. (2009). Statistical power analyses using G*Power 3.1: Tests for correlation and regression analyses. Behavior Research Methods, 41, 1149-1160. doi:10.3758/BRM.41.4.1149

Festa, C. C., \& Ginsburg, G. S. (2011). Parental and peer predictors of social anxiety in youth. Child Psychiatry and Human Development, 42, 291-306. doi:10.1007/s10578-011-0215-8

Field, A. (2005). Discovering statistics using SPSS. Thousand Oaks, CA: Sage.

Fordham, K., \& Stevenson-Hinde, J. (1999). Shyness, friendship quality, and adjustment during middle childhood. Journal of Child Psychology and Psychiatry, 40, 757-768. doi:10.1111/1469-7610.00491 
Furman, W., \& Buhrmester, D. (1992). Age and sex differences in perceptions of networks and personal relationships. Child Development, 73, 241-255. doi:10.2307/1130905

Gazelle, H., Putallaz, M., Li, Y., Grimes, C. L., Kupersmidt, J. B., \& Coie, J. D. (2005). Anxious solitude across contexts: Girls' interactions with familiar and unfamiliar peers. Child Development, 76, 227-246.

Gazelle, H., \& Rudolph, K. D. (2004). Moving toward and away from the world: Social approach and avoidance trajectories in anxious solitary youth. Child Development, 75, 829-849. doi:10.1111/j.1467-8624.2004.00709.x

Gerard, A. B. (2000). Manual for the parent-child relationship inventory (PCRI). Los Angeles, CA: Western Psychological Services.

Greco, L. A., \& Morris, T. L. (2002). Paternal child-rearing style and child social anxiety: Investigation of child perceptions and actual father behavior. Journal of Psychopathology and Behavioral Assessment, 24, 259-267. doi:10.1023/A:1020779000183

Greco, L. A., \& Morris, T. L. (2005). Factors influencing the link between social anxiety and peer acceptance: Contributions of social skills and close friendships during middle childhood. Behavior Therapy, 36, 197-205. doi:10.1016/S0005-7894(05)80068-1

Heerey, E. A., \& Kring, A. M. (2007). Interpersonal consequences of social anxiety. Journal of Abnormal Psychology, 116, 125-134. Doi:10.1037/0021-843X.116.1.125

Hodges, E. E., Malone, M. J., \& Perry, D. G. (1997). Individual risk and social risk as interacting determinants of victimization in the peer group. Developmental Psychology, 33, 1032-1039. Doi:10.1037/0012-1649.33.6.1032

Hudson, J. L., \& Rapee, R. M. (2001). Parent-child interactions and anxiety disorders: An observational study. Behaviour Research and Therapy, 39, 1411-1427. 


\section{Doi:10.1016/S0005-7967(00)00107-8}

Isley, S. L., O’Neil, R., Clatfelter, D., \& Parke, R. D. (1999). Parent and child expressed affect and children's social competence: Modeling direct and indirect pathways. Developmental Psychology, 35, 547-560. doi:10.1037/0012-1649.35.2.547

Keijsers, L., \& Poulin, F. (2013). Developmental changes in parent-child communication throughout adolescence. Developmental Psychology, 49, 2301-2308. doi:10.1037/a0032217

Kochanska, G. (1992). Children's interpersonal influence with mothers and peers. Developmental Psychology, 28, 491-499. doi:10.1037/0012-1649.28.3.491

Krohne, H. W., \& Hock, M. (1991). Relationships between restrictive mother-child interactions and anxiety of the child. Anxiety Research, 4, 109-124. doi:10.1080/08917779108248768

Ladd, G. W. (1990). Having friends, keeping friends, making friends, and being liked by peers in the classroom: Predictors of children's early school adjustment? Child Development, 61, 10811100. doi:10.2307/1130877

La Greca, A. M., \& Harrison, H. M. (2005). Adolescent peer relations, friendships, and romantic relationships: Do they predict social anxiety and depression? Journal of Clinical Child and Adolescent Psychology, 34, 49-61.

La Greca, A. M., \& Lopez, N. (1998). Social anxiety among adolescents: Linkages with peer relations and friendships. Journal of Abnormal Child Psychology, 26, 83-94.

Leary, M. R., Kowalski, R. M., \& Campbell, C. D. (1988). Self-presentational concerns and social anxiety: The role of generalized impression expectancies. Journal of Research in Personality, 22, 308-321. doi:10.1016/0092-6566(88)90032-3

Lewis-Morrarty, E., Degnan, K. A., Chronis-Tuscano, A., Rubin, K. H., Cheah, C. L., Pine, D. S., \& ... Fox, N. A. (2012). Maternal over-control moderates the association between early childhood behavioral inhibition and adolescent social anxiety symptoms. Journal of Abnormal 
Child Psychology, 40, 1363-1373. doi:10.1007/s10802-012-9663-2

Lollis, S., Ross, H., \& Tate, E. (1992). Parents' regulation of children's peer interactions: Direct influences. In R. D. Parke \& G. W. Ladd (Eds.), Family-peer relationships: Modes of linkage (pp. 255-281). Hillsdale, NJ: Lawrence Erlbaum.

McDowell, D. J., \& Parke, R. D. (2009). Parental correlates of children's peer relations: An empirical test of a tripartite model. Developmental Psychology, 45, 224-235. doi:10.1037/a0014305

McFadden, M. (2009). Parent social engagement: Associations with early adolescents' social skills and social anxiety. (Unpublished master's thesis). University of Kansas, Lawrence, KS.

McLeod, B.D., Wood, J.J., \& Weisz, J.R. (2007). Examining the association between parenting and childhood anxiety: A meta-analysis. Clinical Psychology Review, 27, 155-172. doi:10.1016/j.cpr.2006.09.002

Morris, T. L. (2001). Social phobia. In M. W. Vasey \& M. R. Dadds (Eds.), The developmental psychopathology of anxiety (pp. 435-458). New York: Oxford.

Morris, T.L. (2004). Social development. In T.L. Morris, and J.S. March (Eds.), Anxiety disorders in children and adolescents ( $2^{\text {nd }}$ ed., pp. 59-70). New York: Guilford.

Morris, T. L., \& Ale, C. M. (2011). Social anxiety. In D. McKay, E. A. Storch (Eds.), Handbook of child and adolescent anxiety disorders (pp. 289-301). New York: Springer. doi:10.1007/978-1-4419-7784-7_20

Osborne, J. W. (2010). Improving your data transformations: Applying the Box-Cox transformation. Practical Assessment, Research, \& Evaluation, 15, 1-9.

Parke, R. D., \& Ladd, G. W. (Eds.). (1992). Family-peer relationships: Modes of Linkage. Hillsdale, NJ: Lawrence Erlbaum. 
Parker, G. (1979). Reported parental characteristics in relation to trait depression and anxiety levels in a non-clinical group. Australian and New Zealand Journal of Psychiatry,13, 260-264. doi:10.3109/00048677909159146

Parker, G. (1981). Parental representations of patients with anxiety neurosis. Acta Psychiatrica Scandinavica, 63, 33-36. doi:10.1111/j.1600-0447.1981.tb00647.x

Parker, J. G., \& Asher, S. R. (1987). Peer relations and later personal adjustment: Are lowaccepted children at risk? Psychological Bulletin, 102, 357-389. doi:10.1037/00332909.102.3.357

Parker, J. G., \& Asher, S. R. (1993). Friendship and friendship quality in middle childhood: Links with peer group acceptance and feelings of loneliness and social dissatisfaction. Developmental Psychology, 29, 611-621. doi:10.1037/00121649.29.4.611

Piaget, J. (1932). The moral judgment of the child. Oxford: Harcourt.

Preacher, K. J., \& Hayes, A. F. (2008). Asymptotic and resampling strategies for assessing and comparing indirect effects in multiple mediator models. Behavior Research Methods, 40, 879-891.

Pilkonis, P. A. (1977). The behavioral consequences of shyness. Journal of Personality, 45, 596611. doi:10.1111/j.1467-6494.1977.tb00174.x

Putallaz, M. (1987). Maternal behavior and children's sociometric status. Child Development, 58, 324340. doi: $10.2307 / 1130510$

Putallaz, M., \& Heflin, A. H. (1990). Parent-child interaction. In S. R. Asher \& J. D. Coie (Eds.), Peer rejection in childhood (pp. 189-216). New York: Cambridge.

Rapee, R. M. (1997). Potential role of childrearing practices in the development of anxiety and depression. Clinical Psychology Review, 17, 47-67. doi:10.1016/S0272-7358(96)00040-2

Rodebaugh, T. L. (2009). Social phobia and perceived friendship quality. Journal of Anxiety 
Disorders, 23, 872-878. doi:10.1016/j.janxdis.2009.05.001

Rodebaugh, T. L., Fernandez, K. C., \& Levinson, C. A. (2012). Testing the effects of social anxiety disorder on friendship quality across gender and ethnicity. Cognitive Behaviour Therapy, 41, 130-139. doi:10.1080/16506073.2012.661451

Rork, K. E., \& Morris, T. L. (2009). Influence of parenting factors on childhood social anxiety: Direct observation of parental warmth and control. Child \& Family Behavior Therapy, 31, 220-235. doi:10.1080/07317100903099274

Rose, A. J. (2002). Co-rumination in the friendships of girls and boys. Child Development, 73, 18301843. doi:10.1111/1467-8624.00509

Rose, A. J., \& Rudolph, K. D. (2006). A review of sex differences in peer relationship processes: Potential trade-offs for the emotional and behavioral development of girls and boys. Psychological Bulletin, 132, 98-131. doi:10.1037/0033-2909.132.1.98

Rubin, K. H., Daniels-Beirness, T., \& Bream, L. (1984). Social isolation and social problem solving: A longitudinal study. Journal of Consulting and Clinical Psychology, 52, 17-25. doi:10.1037/0022-006X.52.1.17

Rubin, K. H., Wojslawowicz, J. C., Rose-Krasnor, L., Booth-Laforce, C., \& Burgess, K. B. (2006). The best friendships of shy/withdrawn children: Prevalence, stability, and relationship quality. Journal of Abnormal Child Psychology, 34, 143-157. doi:10.1007/s10802$005-9017-4$

Schneider, B. (1999). A multi-method exploration of the friendships of children considered socially withdrawn by their school peers. Journal of Abnormal Child Psychology, 27, 115-123. doi:10.1023/A:1021959430698

Schneider, B. H. (2009). An observational study of the interactions of socially 
withdrawn/anxious early adolescents and their friends. Journal of Child Psychology and Psychiatry, 50, 799-806. doi:10.1111/j.1469-7610.2008.02056.x

Selman, R. L. (1981). The development of interpersonal competence: The role of understanding in conduct. Developmental Review, 1, 401-422. doi:10.1016/0273-2297(81)90034-4

Shapiro, S. S., \& Wilk, M. B. (1965). An analysis of variance test for normality (complete samples). Biometrika, 52, 591-611. doi:10.1093/biomet/52.3-4.59

Silk, J. S., Morris, A. S., Kanaya, T., \& Steinberg, L. (2003). Psychological control and autonomy granting: Opposite ends of a continuum or distinct constructs? Journal of Research on Adolescence, 13, 113-128. doi:10.1111/1532-7795.1301004

Siqueland, L., Kendall, P. C., \& Steinberg, L. (1996). Anxiety in children: Perceived family environments and observed family interaction. Journal of Clinical Child Psychology, 25, 225237. doi:10.1207/s15374424jccp2502_12

Sparrevohn, R. M., \& Rapee, R. M. (2009). Self-disclosure, emotional expression and intimacy within romantic relationships of people with social phobia. Behaviour Research and Therapy, 47, 1074-1078. doi:10.1016/j.brat.2009.07.016

Spence, S. H., Donovan, C., \& Brechman-Toussaint, M. (1999). Social skills, social outcomes, and cognitive features of childhood social phobia. Journal of Abnormal Psychology, 108, 211-221. doi:10.1037/0021-843X.108.2.211

Starr, L. R., \& Davila, J. (2008). Differentiating interpersonal correlates of depressive symptoms and social anxiety in adolescents: Implications for models of comorbidity. Journal of Clinical Child and Adolescent Psychology, 37, 337-349. doi:10.1080/15374410801955854

Steinberg, L., \& Silverberg, S. B. (1986). The vicissitudes of autonomy in early adolescence. Child Development, 57, 841-851. doi:10.2307/1130361 
Sullivan, H. (1953). The interpersonal theory of psychiatry. New York: Norton.

Tabachnick, B. G., \& Fidell, L. S. (2007). Using multivariate statistics (5th ed.). Boston, MA: Allyn \& Bacon.

Tillfors, M., Persson, S., Willén, M., \& Burk, W. J. (2012). Prospective links between social anxiety and adolescent peer relations. Journal of Adolescence, 35, 1255-1263. doi:10.1016/j.adolescence.2012.04.008

van der Bruggen, C. O., Stams, G. M., \& Bögels, S. M. (2008). Research review: The relation between child and parent anxiety and parental control: A meta-analytic review. Journal of Child Psychology and Psychiatry, 49, 1257-1269. doi:10.1111/j.14697610.2008.01898.x

Verhoeven, M., Bögels, S. M., \& van der Bruggen, C. C. (2012). Unique roles of mothering and fathering in child anxiety; moderation by child's age and gender. Journal of Child and Family Studies, 21, 331-343. doi:10.1007/s10826-011-9483-y

Vernberg, E. M., Abwender, D. A., Ewell, K. K., Beery, S. H. (1992). Social anxiety and peer relationships in early adolescence: A prospective analysis. Journal of Clinical Child Psychology, 21, 189-196. doi:10.1207/s15374424jccp2102_11

Weeks, J. W., Rodebaugh, T. L., Heimberg, R. G., Norton, P. J., \& Jakatdar, T. A. (2009). “To avoid evaluation, withdraw:" Fears of evaluation and depressive cognitions lead to social anxiety and submissive withdrawal. Cognitive Therapy and Research, 33, 375-389. doi:10.1007/s10608-008-9203-0

Wenzel, A., Graff-Dolezal, J., Macho, M., \& Brendle, J. R. (2005). Communication and social skills in socially anxious and nonanxious individuals in the context of romantic relationships. Behaviour Research and Therapy, 43, 505-519. 
doi:10.1016/j.brat.2004.03.010

Westenberg, P., Gullone, E., Bokhorst, C. L., Heyne, D. A., \& King, N. J. (2007). Social

evaluation fear in childhood and adolescence: Normative developmental course and continuity of individual differences. British Journal of Developmental Psychology, 25, 471-483. doi:10.1348/026151006X173099 


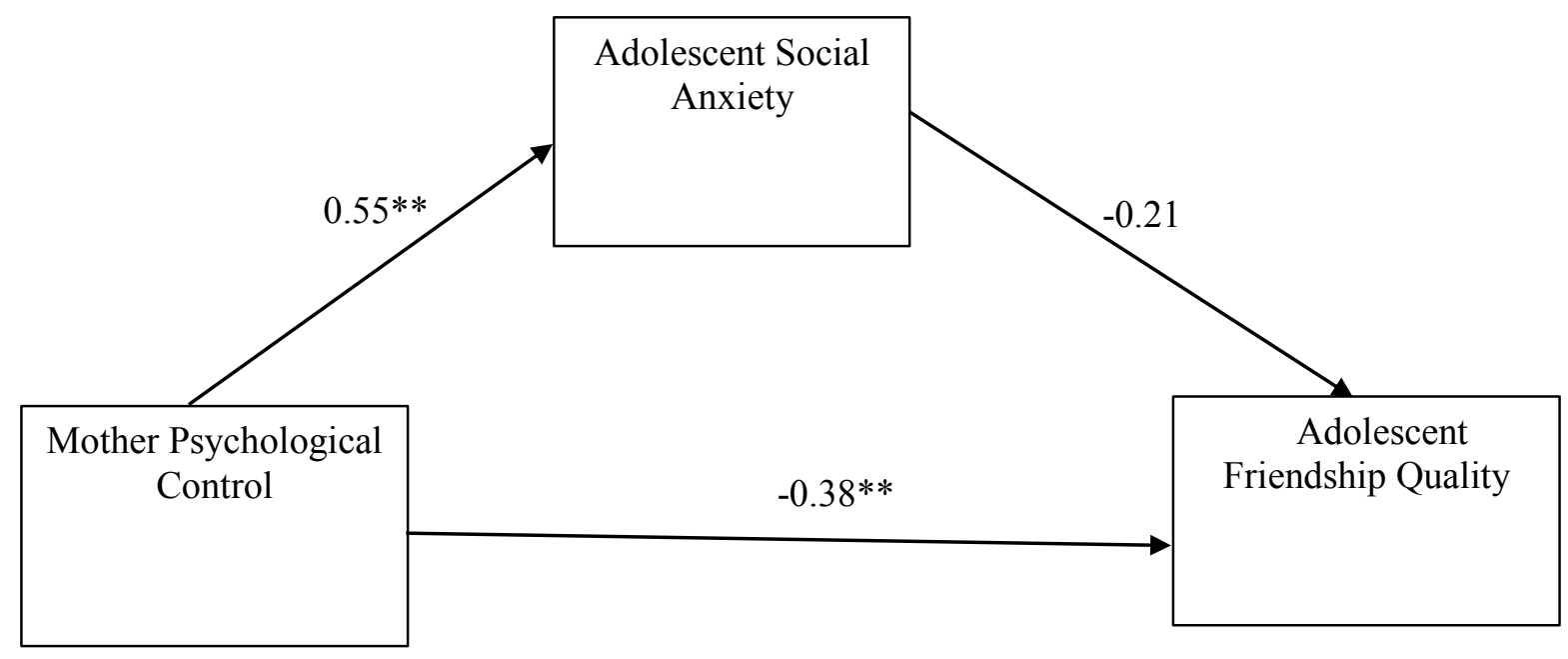

Figure 1. Mediation of the Relation between Maternal Psychological Control and Adolescent Friendship Quality by Adolescent Social Anxiety

Note: $* * \mathrm{p}<.001$ 


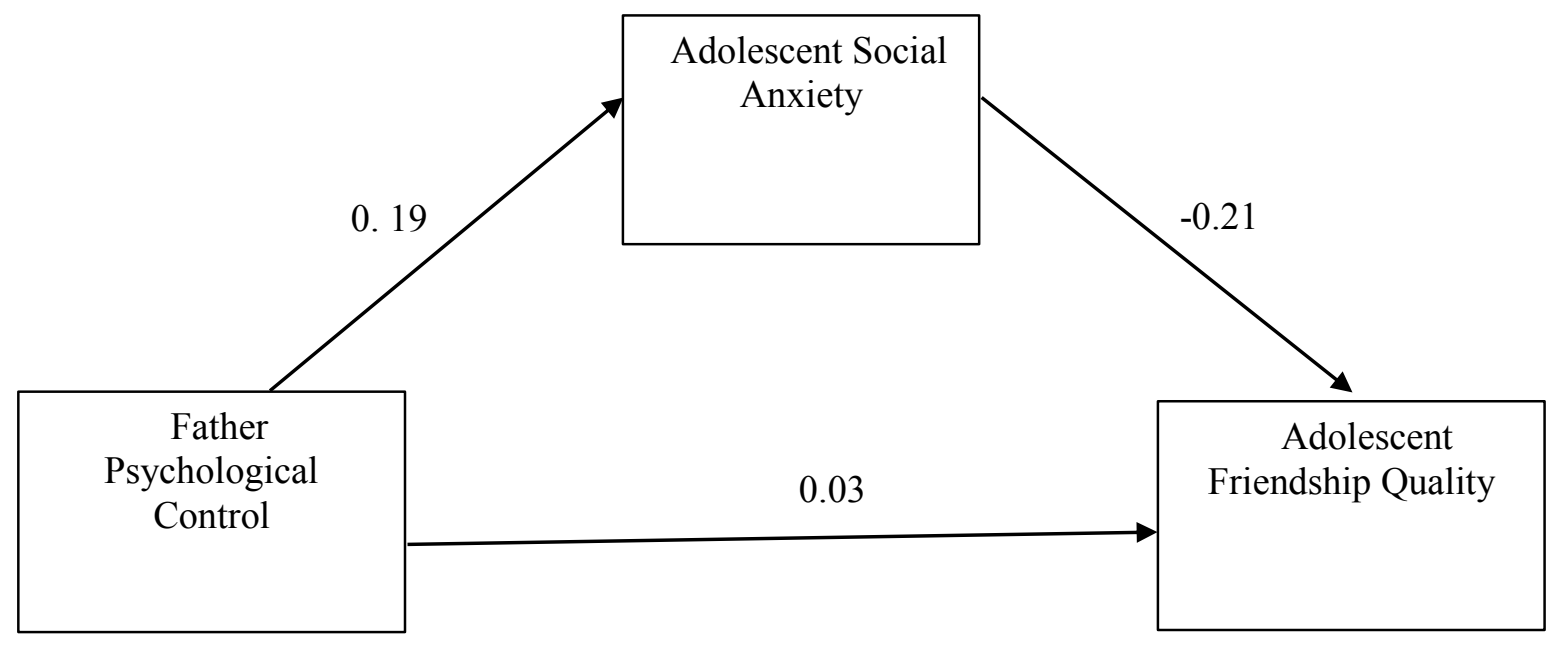

Figure 2. Mediation of the Relation between Paternal Psychological Control and Adolescent Friendship Quality by Adolescent Social Anxiety 


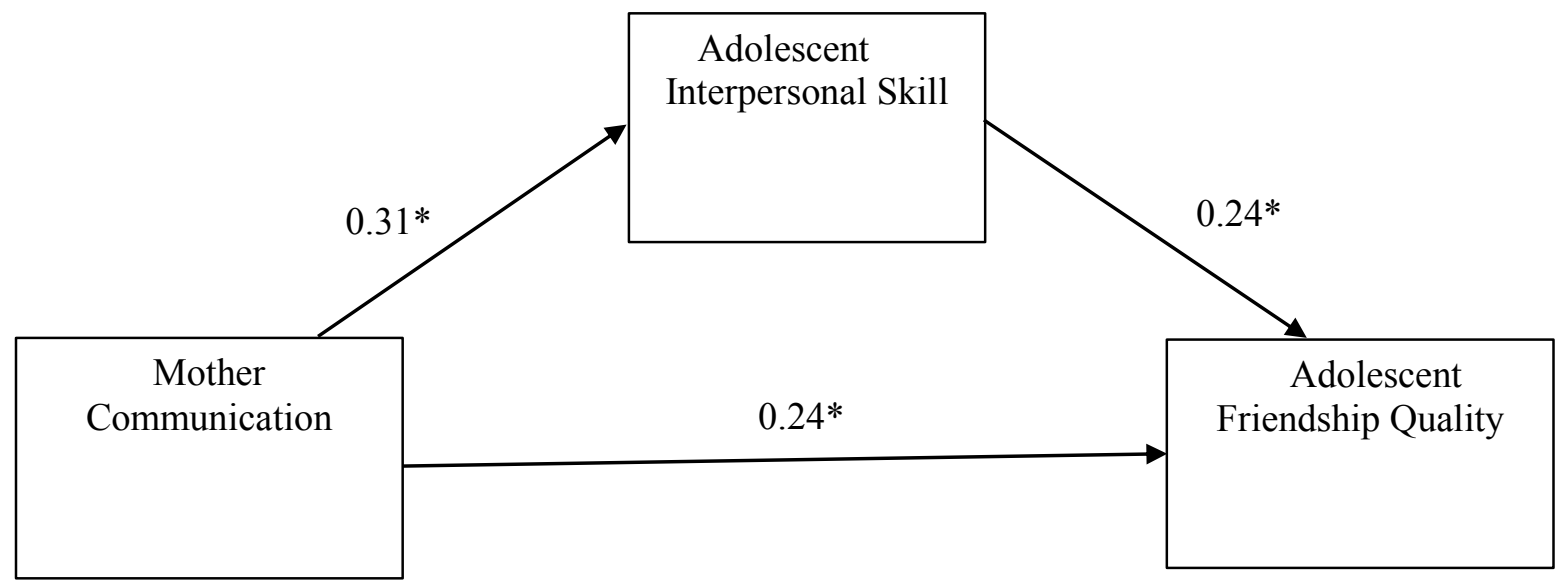

Figure 3. Mediation of the Relation between Maternal Communication and Adolescent Friendship Quality by Adolescent Interpersonal Skill

Note: ${ }^{*} \mathrm{p}<.05$ 


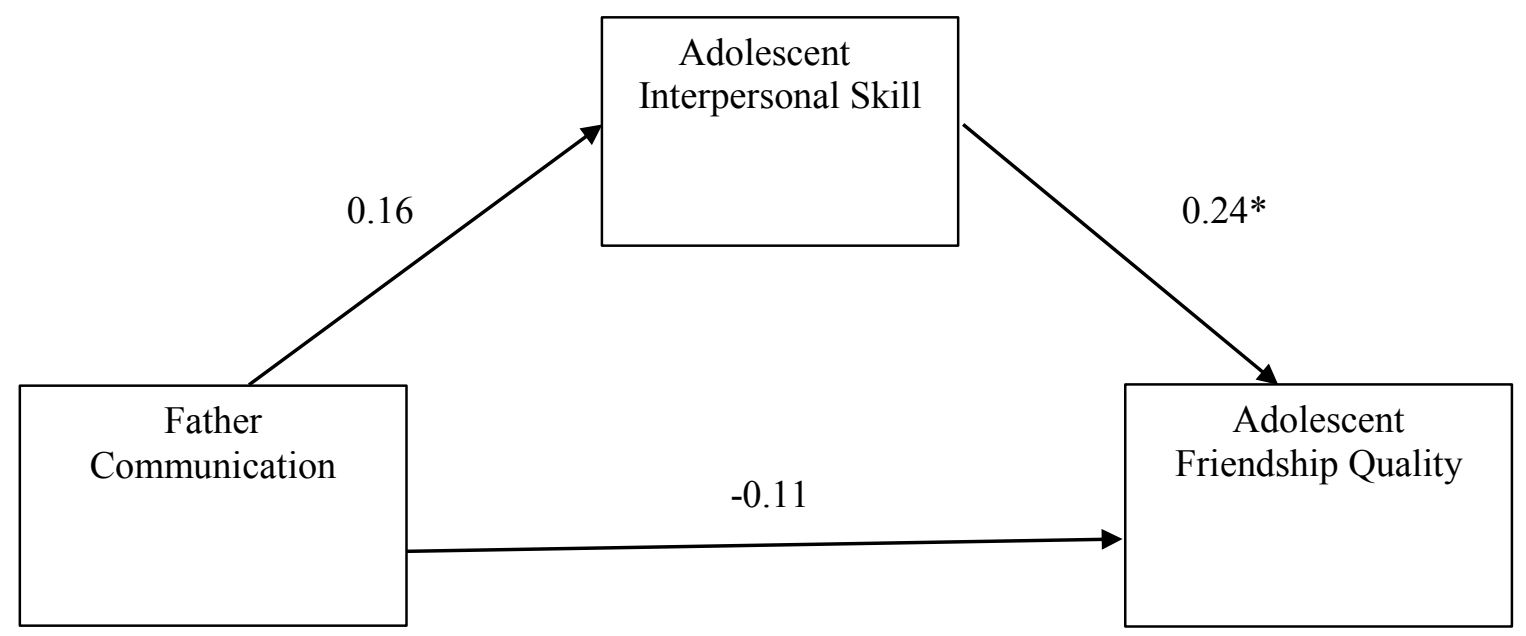

Figure 4. Mediation of the Relation between Paternal Communication and Adolescent Friendship Quality by Adolescent Interpersonal Skill

Note: ${ }^{*} p<.05$ 
Table 1. Demographic Characteristics of Participants

$\begin{array}{lll}\text { Adolescents } & \text { Mothers }\end{array}$

\begin{tabular}{|c|c|c|c|c|c|c|}
\hline Race & $n$ & Percent & $n$ & Percent & $n$ & Percent \\
\hline Caucasian/White & 38 & 57 & 41 & 61 & 38 & 57 \\
\hline AA/Black & 15 & 22 & 15 & 22 & 19 & 28 \\
\hline Asian American & 4 & 6 & 4 & 6 & 4 & 6 \\
\hline $\mathrm{AI} / \mathrm{AN}$ & 0 & 0 & 1 & 2 & 0 & 0 \\
\hline Multi-racial & 8 & 12 & 2 & 2 & 2 & 3 \\
\hline Not reported & 2 & 3 & 4 & 4 & 4 & 6 \\
\hline \multicolumn{7}{|l|}{ Ethnicity } \\
\hline Hispanic & 8 & 12 & 7 & 10 & 5 & 8 \\
\hline Non-Hispanic & 55 & 82 & 56 & 84 & 64 & 85 \\
\hline Not Reported & 4 & 6 & 4 & 6 & 6 & 8 \\
\hline \multicolumn{7}{|l|}{ Education } \\
\hline Graduate Degree & & & 22 & 33 & 24 & 36 \\
\hline College Degree & & & 32 & 48 & 25 & 37 \\
\hline High School & & & 12 & 18 & 13 & 19 \\
\hline$<$ High School & & & 0 & 0 & 2 & 3 \\
\hline Not Reported & & & 1 & 2 & 3 & 5 \\
\hline
\end{tabular}


Table 2. Descriptive Statistics for Variables

\begin{tabular}{|c|c|c|c|c|c|}
\hline & $\mathrm{N}$ & Mean & SD & Minimum & Maximum \\
\hline \multicolumn{6}{|l|}{ Father-report } \\
\hline PCRI Autonomy & 67 & 24.70 & 5.26 & 12 & 34 \\
\hline PCRI Communication & 67 & 17.91 & 6.64 & 9 & 33 \\
\hline \multicolumn{6}{|l|}{ Mother-report } \\
\hline PCRI Autonomy & 67 & 23.74 & 5.64 & 10 & 34 \\
\hline PCRI Communication & 67 & 19.33 & 8.19 & 9 & 36 \\
\hline \multicolumn{6}{|l|}{ Adolescent Report } \\
\hline Father PCS & 66 & 1.41 & 0.51 & 1 & 2.75 \\
\hline Mother PCS & 67 & 1.23 & 0.29 & 1 & 2.13 \\
\hline FQQ & 67 & 14.58 & 3.63 & 6.79 & 20.00 \\
\hline AICQ & 66 & 3.47 & 0.66 & 1.45 & 4.63 \\
\hline SPAI-C & 67 & 13.22 & 10.51 & 0 & 43.35 \\
\hline
\end{tabular}


Table 3. Differences in Variables by Race

\begin{tabular}{|c|c|c|c|c|c|c|}
\hline & & $N$ & $M$ & $S D$ & $t$ & $p$ \\
\hline \multicolumn{7}{|l|}{ Father PCRI Communication } \\
\hline & Non-White & 27 & 17.93 & 6.18 & 0.36 & 0.72 \\
\hline & White & 38 & 17.34 & 6.74 & & \\
\hline \multicolumn{7}{|l|}{ Father PCRI Autonomy } \\
\hline & Non-White & 27 & 22.41 & 4.29 & -3.50 & $0.01 * *$ \\
\hline & White & 38 & 26.50 & 4.88 & & \\
\hline \multicolumn{7}{|l|}{ Mother PCRI Communication } \\
\hline & Non-White & 27 & 20.37 & 8.65 & 1.15 & 0.25 \\
\hline & White & 38 & 18.03 & 7.65 & & \\
\hline \multicolumn{7}{|l|}{ Mother PCRI Autonomy } \\
\hline & Non-White & 27 & 20.70 & 6.00 & -4.55 & $0.00 * *$ \\
\hline & White & 38 & 26.29 & 3.90 & & \\
\hline \multicolumn{7}{|l|}{ Father PCS } \\
\hline & Non-White & 27 & 0.13 & 0.12 & -0.34 & 0.73 \\
\hline & White & 37 & 0.14 & 0.10 & & \\
\hline \multicolumn{7}{|l|}{ Mother PCS } \\
\hline & Non-White & 27 & 0.07 & 0.12 & -0.99 & 0.33 \\
\hline & White & 38 & 0.08 & 0.11 & & \\
\hline \multicolumn{7}{|l|}{ AICQ } \\
\hline & Non-White & 27 & 3.57 & 0.56 & 1.44 & 0.16 \\
\hline & White & 37 & 3.34 & 0.70 & & \\
\hline \multicolumn{7}{|l|}{ SPAI-C } \\
\hline & Non-White & 27 & 10.95 & 10.04 & -1.78 & 0.08 \\
\hline & White & 38 & 15.54 & 10.36 & & \\
\hline \multicolumn{7}{|l|}{ FQQ } \\
\hline & Non-White & 27 & 15.54 & 3.15 & 1.84 & 0.07 \\
\hline & White & 38 & 13.92 & 3.72 & & \\
\hline
\end{tabular}

Note: ${ }^{*} p<.05 . * * p<.01$. Comparisons were done using transformed data for the PCS. PCRI is Parent Child Relationship Inventory. PCS is Parental Control Scale. AICQ is Adolescent Interpersonal Competence Questionnaire. SPAI-S is Social Phobia and Anxiety Inventory for Children. FQQ is Friendship Quality Questionnaire. 
Table 4. Correlations between Variables

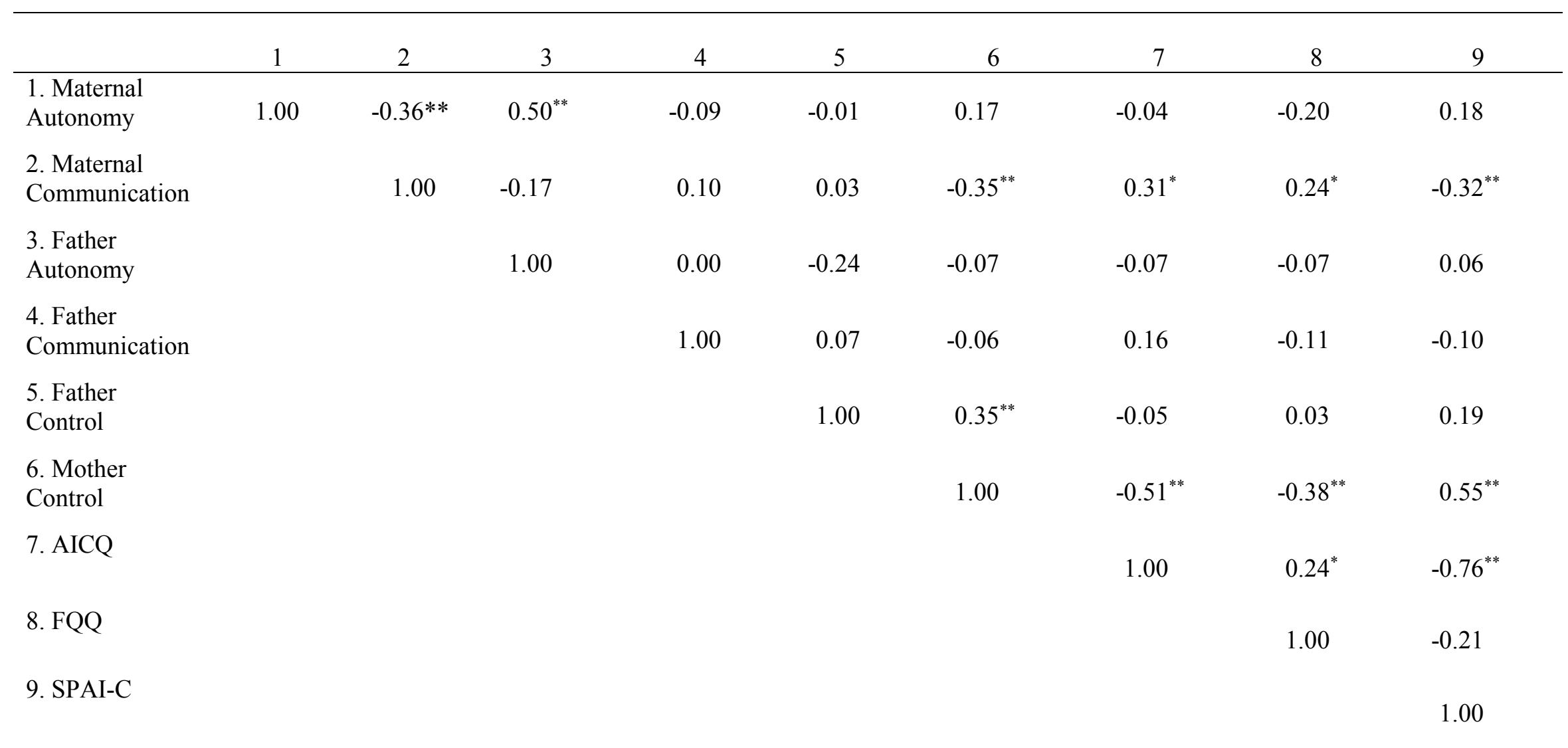

\footnotetext{
Note: ${ }^{* *} \mathrm{p}<0.01,{ }^{*} \mathrm{p}<0.05$. Maternal and Paternal Autonomy and Communication scores are from Parent Child Relationship Inventory. Maternal and Paternal Control scores are from the Parental Control Scale. AICQ is Adolescent Interpersonal Competence Questionnaire. FQQ is Friendship Quality Questionnaire. SPAI-C is Social Phobia and Anxiety Inventory for Children.
} 
Appendix A.

\section{Information about You and Your Family \\ Parent Report}

1. What is your name?

2. What is your child's name?

3. What is your age?

4. What is your child's date of birth?

5. What is your relationship to the child?

6. What is your child's sex?
A. Male
B. Female

7. What is your race?
A. American Indian or Alaskan Native
B. Asian or Pacific Islander
C. Black
D. White

8. What is your ethnicity?
A. Hispanic
B. Non-Hispanic

9. What is your child's race?
A. American Indian or Alaskan Native
B. Asian or Pacific Islander
C. Black 
D. White

10. What is your child's ethnicity?
A. Hispanic
B. Non-Hispanic

11. Occupation: Please provide your job position or title, NOT the name of your employer. For example, if you are a teacher at the local high school, please state "high school teacher". If you are retired, please state "retired" as well as your prior occupation. If you do not work outside the home, please state "stay at home parent" or "unemployed"

12. What is the highest level of education you have completed?
A. Did not finish High School
B. High School
C. College Degree
D. Graduate Degree

13. Please complete the following information about your spouse or partner (if applicable).

Name:

Occupation:

14. What is your spouse or partner's race?
A. American Indian or Alaskan Native
B. Asian or Pacific Islander
C. Black
D. White

15. What is your spouse or partner's ethnicity?
A. Hispanic
B. Non-Hispanic 